\title{
DESIGN OPTIMIZATION OF LATTICE GIRDERS ACCORDING TO MEMBER AND JOINT-RELATED DESIGN CONSTRAINTS
}

\author{
Tugrul Talaslioglu* \\ Osmaniye Korkut Ata University, Department of Civil Engineering, 80000, Osmaniye/Turkey \\ *(Corresponding author: E-mail: ttalaslioglu@osmaniye.edu.tr, talaslioglu@cu.edu.tr)
}

\section{A B S T R A C T}

This study concerns with the design optimization of geometrically nonlinear lattice girders. The novelty of this study comes from simultaneously using the member and joint related design constraints, which are borrowed from the provisions of API RP2A-LRFD specification and defined depending on both member and joint strengths. A multi-objective design optimization approach named ImpNSGAII, which was improved in way of integrating both a neural network implementation and an automatic generating lattice girder tool for the search mechanism of NSGAII, is utilized in this study. Hence, this study purposes to investigate how to vary the optimality quality depending on the presence of joint strength-related design constraints. Thus, it is demonstrated that the presence of the joint strengthrelated design constraints causes to a divergence in the construction cost of optimal designs. Consequently, it is proved that the ImpNSGAII has a higher capability of exploring a conceptual lattice girder configuration in order to obtain an optimal design satisfying the economy, load-resistance and serviceability-related design conditions at the same time.
ART I CLE H IS T ORY

$\begin{array}{ll}\text { Received: } & \text { 12 June } 2020 \\ \text { Revised: } & \text { 2 February } 2021 \\ \text { Accepted: } & \text { 6 February } 2021\end{array}$

\section{K E Y W O R D S}

Multiple objectives;

Lattice girder;

Geometric nonlinearity;

API RP2A-LRFD ;

Member \& Joint Strength

\section{Introduction}

The steel lattice girders, members of which are connected to each other making use of a welding process, bolts and etc., are widely utilized in the structural engineering field (for example roofs, bridge, industrial applications etc.) [1]. In order to both increase its manufacturing accuracy and decrease its construction cost; they are preferably constructed in a manufacturing fabric of steel structures using a number of robots for the welding process [2]. Therefore, the effect of excessive welding process on the joint strength has to be considered in the design phase of lattice girder. Hence, the complexity in the design of lattice girders with respect to the generational design approach is correspondingly increased. Moreover, an increased demand to the cost-saving design of lattice girder causes to emerge the additional design complexities. In fact, these design complexities, which are exhaustively tackled in this section, constitutes the fundamentals of ImpNSGAII.

A generational design approach is also utilized in the design of steel lattice girders. It begins by deciding a certain geometric and topologic configuration of lattice girder since the various conceptual models such as Warren, Pratt and etc. has been successfully utilized to represent its framing configuration [3-4]. Following the decision on the conceptual model of lattice girder, its member cross-sectional properties are determined. Then, the sizes of lattice girder members are determined according to a database, which contains the cross-sectional properties of steel profiles. For this purpose, the member responses are computed using a linear structural analysis method. However, when the deformation in the geometrical shape of lattice girder is large, the structural responses are not correctly computed. Because, the large deformations of joints cause to arise the additional responses in the lattice girder members. Therefore, an appropriate approach is the usage of a non-linear structural analysis method for the computation of the member and joint responses. [5-8]. Following the computation of member responses, the capacities of member strengths is checked according to an available national or international design code [9]. Therefore, the designer's experience has a big importance in this stage in order to reduce the number of trials.

This generational design procedure has still been applied to determine the most suitable construction of lattice girder. However, the best way for the exploration of a cost-effective lattice girder design in a lower trial number is the inclusion of an optimization process into the design procedure [10-11].

In the optimal design of steel structures, the economy is provided in a way of arranging the cross-sectional properties of its members for a lower weight of steel structures. In this generational sizing optimization procedure, the member cross-sectional properties are determined by checking the member stress and joint displacement values according to their pre-specified upper values [12]. Although there is a big variety in the steel profiles with different cross-sectional shapes and properties, the circular-hollow-shaped cross-sections are preferably utilized to represent the size type design variables. Because, their torsional strengths are higher than those with open cross-sections [13-16]. It was shown that an execution of this generational sizing optimization procedure causes to decrease the number of feasible solutions [17]. Furthermore, it was also demonstrated that involving the shape and geometry of lattice girder into the optimal design procedure leads to the exploration of optimal design with higher economic, serviceability and load-resistance capability. Particularly, it was also shown that the stability capacity of steel structure was increased through the various arrangements in its current geometrical form [18]. Therefore, using a conceptual model for the representation of lattice girder framing configurations provides a big advantage in introducing the shape and geometric properties of lattice girders. It is noted that the appropriateness of conceptual design model has a big importance on the construction of lattice girder in the manufacturing fabrics of steel structures due to its practically applicability into the real world [19]. Hence, the waste of time in the elimination of inappropriate optimal designs obtained is prevented.

The generational optimal design procedure is utilized in the design optimization of steel structures with single objective function, for example, weight minimization. But the designer preferences are correspondingly neglected [2021]. In order to handle this bottleneck, a multi-objective optimization procedure should be utilized in the optimal design of steel structures. Hence, it is possible to make a tradeoff analysis among the designer's preferences. Furthermore, the proposed multi-objective optimization approach has to also be capable of handling with the usage of mixing type of design variables due to the discrete nature of steel structures. Furthermore, it must own a simple but an effective search mechanism in order to reduce the computing time in the exploration of optimal designs with higher quality as well [17].

The effectiveness of any multi-objective optimization procedure depends on the properly assignment of their governing parameters. Thus, the computing performance of multi-objective optimization algorithm is correspondingly increased. But, the computing performance of proposed multi-objective optimization algorithm is degraded when the current parameter value set is utilized for the different optimization problem [22-24]. Thus, it is concluded that the adaptively usage of governing parameters is the most crucial issue in the evaluation of computing performance of multi-objective optimization algorithm since the form of solution space varies depending on the nature of optimization problem. The evaluation of multi-objective optimization procedures is distinguished from the ones with single objective due to the increased number of objective functions. The computing capability of any optimization procedure with single objective function is easily determined considering the convergence degree of optimal designs. However, the computing performance of multi-objective optimization procedure is assessed using a statistical test approach performed to evaluate the values of various quality criterions [25].

Particularly, the multi-objective optimization approaches that mimic the various nature-related phenomena such as, Darwin's evolutionary theory, livings of ants, bees, flying etc. are more successful in the design optimization of both steel structural and the other engineering applications [26]. Particularly, the genetic algorithm based multi-objective optimization algorithms achieve to 
take more attention in the various optimization-related fields due to their simple and effective search mechanisms [27].

This study concerns with the optimal design of geometrically nonlinear tubular lattice girders considering the provisions of "Recommended Practice for Planning, Designing and Constructing Fixed Offshore Platforms: Load and Resistance: Factor Design (API RP2A-LRFD 1993) [28]. It is noted that API RP2A-LRFD is a compact design code since it comprises the member and jointstrength-related design codes. The arc-length method is employed to analyze the structural system in order to compute nonlinear structural responses at each load steps. The arc-length approach is proven to be successful in the identification of limit points, which indicates the failure in the stability of structural system, thereby iteratively tracing an equilibrium path formed by incremental load and displacement values [18]. Hence, the higher complex nonlinear structural problems that exhibits snap-through or snap-back behavior are easily solved through its capability of easily predicting the limit points (bifurcation, branching and etc.). An improved multi-objective optimization approach (ImpNSGAII) is utilized to execute the optimization-related computations [17]. The fundamentals of ImpNSGAII are constituted on the computing procedure of nondominated sorting genetic algorithm II (NSGAII), which is basically governed by the genetic operators. The main future of ImpNSGAII is its ability of self adaptively adjusting the parameter values of genetic operators.

The novelty of this study comes from its being a first attempt to determine the load-resistance capability of the lattice girder at any load step of the nonlinear structural analysis approach thereby checking both member and joint strengths considering the provisions of API RP2A-LRFD specification [28]. The other novel aspect of this study is that the proposed optimal design approach does not penalized the objective functions. Hence, a waste of time consumed in the exploration of feasible designs is correspondingly prevented through this feature of the proposed design approach.

The presentation of optimal design results starts firstly by introducing a multi-objective optimization background. The computing steps of ImpNSGAII are defined in the subsequent sections. The design results outcome from the application examples, which were introduced in Reference [17], are also included. Then, a general summarization is reported in the section of "conclusion".

\section{The basic elements of proposed optimization procedure}

The design optimization of lattice girders that satisfies the economy, loadresistance and serviceability-related design conditions at the same time is carried out thereby minimizing the entire weight of lattice girder $f_{l}$ and joint displacements $f_{2}$ and maximizing its member forces $f_{3}$ (see Eqns. (1-3)). The proposed objective functions are formulated as:

$$
f_{1}=\min \left(\sum_{k=1}^{m}\left(w^{*} l\right){ }_{\mathrm{k}}\right) \quad(k=1, . ., m)
$$

$f_{2}=\min \left(d_{\mathrm{ij}}\right)$

$$
(i=1, . ., 6 \text { and } j=1, \ldots, n)
$$

$$
f_{3}=\max \left(f_{\mathrm{ij}}\right)
$$

The entire weight $W$ is computed considering the structural member length $l$ and its unit weight $w$ for each member $(1, . ., m)$.The properties of structural members with circular hollow shaped cross-sections are assigned from 37 different types-steel profiles. The joint displacements $d_{i j}(j=1, \ldots, n$ and $i=1, \ldots, 6)$ are defined for both each degree of freedom $i$ and joint $j$. The member forces $f_{i j}$, which contain "axial" $\&$ "shear" forces, "bending" $\&$ "torsional" moments, are obtained in the end of execution of nonlinear structural analysis.

The design constraints called as the member and joint related design constraints (MRDC and JRDC), are described using the member and joint strengthrelated inequalities. A unity value is assigned to represent these inequalities (see the sections of " $D$ " and " $E$ " in Reference [28]). For example, the inequalities ( $f_{t}$ $\leq \phi^{*} F$ ) for axial tension are represented by unities as Unity $=\left(\mathrm{f}_{t} / \phi^{*} F\right) \leq 1.0$.

In the following part, the details of design constraints are presented including their formulation numbers along with Tables and Figures no's located in provisions of API RP2A-LRFD specification [28].

i) Member strength-related unities for $m$ members $(k=1, \ldots m)$ :

Unity $^{k}{ }_{\text {Axial }}$ represents the member axial capacity, which defines a strength against tensile and compressive stresses occurred in lattice girder members (see the section of D.2.1-1 and D.2.2-1 in Reference [28]). It is defined by making use of "nominal yield strength" and "nominal axial compressive strength", respectively. Whereas the nominal yield strength has a pre-assigned value, the nominal axial compressive strength is determined depending on both "nominal yield strength" and "elastic\&inelastic local buckling strength" (stability issue). Therefore, the certain parameters, for example the effective length factor for the calculation of braced length along with the gyration diameter and the ratio as "diameter/thickness", manage the magnitude of nominal axial compressive strength. Thus, the availability of diagonal members against the stability problem and the assignment of members with higher thickness for the construction of lattice girder has a big contribution to the member axial capacity.

Unity $_{\text {Shear }}^{k}$ represents the member's shear capacity, which defines a strength against shear stress occurred in lattice girder member (see the section of D.2.4 1 in Reference [28]). The shear capacity of member is determined considering "nominal shear strength", which is indicated as a percentage of "nominal yield strength". As in the Unity ${ }_{\text {Axial }}$, the use of diagonal members provides to decrease the member forces, which comes from the external forces imposed on the corresponding nodes.

Unity $_{\text {AxialCompr\&BendingBuckling }}^{k}$ represents the member's combined axial compressive and bending buckling capacities, which defines the strengths against both compressive and bending stresses (see the section of D.3.2-2 [28]). This unity is computed depending on "euler buckling strength" and "nominal axial compressive strength" (stability issue) along with "nominal bending strength". The computing details about "nominal bending strength" are given in the introduction of Unity ${ }_{\text {Axial }}$, above. The nominal bending strength is calculated depending on a ratio "diameter/thickness" and "elastic\&plastic section modulus". Thus, the availability of diagonal members not only provides a positive contribution to this unity, but the use of members with higher thickness and plastic section modulus also increases the capacity of this unity.

Unity $^{k}{ }_{\text {AxialCompr\&BendingYield }}$ represents the member's combined axial tensile and bending yield capacities, which defines the strengths against both tensile and bending forces (see the section of D.3.1-1 in Reference [28]). This unity is computed depending on "nominal inelastic buckling strength" and "nominal bending strength". The computing details about these strengths are given in the introduction of Unity ${ }_{\text {AxialCompr\&BendingBuckling }}$ and Unity ${ }_{\text {Axial }}{ }_{\text {, respectively. Thus, the }}$ availability of diagonal members and the use of members with higher thickness and plastic section modulus provides an increase in the capacity of this unity.

ii) Joint strength-related unities for $n$ joint $(j=1, \ldots, n)$ :

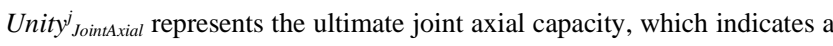
strength against compressive\&tensile and moment forces (see the section of E.3-2 in Reference [28]). Thus, the joint axial capacity is not only determined depending on axial forces, but also, in-plane and out-plane bending forces occurred in lattice girder members along with the joint types (K,T,Y and etc.). Considering, Table E.3-1 and Table E.3-2 in Reference [28], it is seen that Kshaped connections makes more contribution in the capacity of joint axial and thus leads to a decrease in the value of its unity (see Fig. E.3.2 in Reference [28]). Moreover, the contribution of T and Y-shaped connections are lower with respect to K-shaped connections. If a vertical member, axial force of which equals to zero, is connected with only one diagonal member at a joint, this joint is defined as $\mathrm{T}$ and/or T\&Y. Therefore, the inclusion of diagonal members into the construction of lattice girder leads to an increase in the joint axial capacity. Particularly, the joint axial capacity, which is obtained by multiplying the "chord design factor" and "ultimate strength factor" is factorized by a parameter "connection resistance factor". In fact, both connection resistance factor and ultimate strength factor are determined the joint types (K, T, Y and etc.) along with the thickness and diameters of chord and brace members.

Unity $_{\text {JointAxial\&Bending }}$ represents the joint axial and bending capacities (see E.3-4 in Reference [28]). In fact, this unity is computing depending on the ultimate joint axial and bending moment capacities without omitting the parameter "connection resistance factor".

Unity $_{\text {JointYield }}$ represents the joint yield capacity (see the section of E.3-1 in Reference [28]). The strength of joint yield is determined depending on both the pre-defined yield values of brace and chord members and joint geometric properties (brace angle, thickness and diameters of brace and chord members).

It is mentioned that the thickness and diameters of chord and brace members have a big effect on the unity values which are utilized to define JRDCs. In his regard, some arrangements for these cross-sectional properties of chord and brace members provides an increase in the capacities of joint-related strengths as:

i) The thickness of chord member must be higher with respect to its diameter. ii) The thickness of chord member must be higher than brace members' iii) The diameter of chord member must be higher than brace members' iv) Particularly, the lower angle $\theta$ between chord and brace members leads to an increase in the capacity of Unity ${ }_{\text {JointYield }}$ (see Eqn. E.3-1 in Reference [28]). In this study, the lower value of middle height, which is indicated by $\operatorname{Par}_{\mathrm{H} 2}$ is utilized to indicate a lower angle $\theta$. In fact, it has to be also noted that an increase in the middle height of lattice girder causes the occurrence of stability-related structural problem.

If any unities defined for the member and joint strength exceed " 1 ", then nonlinear structural analysis is stopped at the corresponding loading step number. At the corresponding loading step number, maximum member force and 
joint displacement values are utilized to determine both the load-resistance capability and joint displacements for the automatically assigned lattice girder configuration. It is mentioned that the arc-length method is utilized for the analysis of structural responses. For this purpose, a finite element analysis tool, ANSYS is employed to compute the responses for the current lattice girder configuration [17].

Furthermore, the design flexibility of proposed optimal design approach is improved thereby including an automatic lattice girder generating tool into the optimization of lattice girder designs taking into consideration of proposed constraints mentioned above. A typical lattice girder model is used to generate various lattice girders. Thus, it is possible to carry out not only sizing but also topologic and shape optimization at the same time. The size type design variables
D1-D4 and their cross-sectional properties are chosen from 37 different circular-hollow-shaped cross-sections and assuming their limit values Par $_{U D V}$ and $\operatorname{Par}_{L D V}$ in a range of 1-37 (see Reference [17]). The topology type design variables, limits of which are defined by $\operatorname{Par}_{D N U}$ and $P a r_{D N L}$, is governed by a ratio as (length of span $L S$ / division number $\operatorname{Par}_{D N}$ ). Two shape type design variables for two heights of lattice girder $\mathrm{H} 1$ and $\mathrm{H} 2$ are defined by two parameters Par $_{H I}$, $\operatorname{Par}_{\mathrm{H} 2}$. Their limits are determined by the parameters $\operatorname{Par}_{\mathrm{HIU}}, \operatorname{Par}_{\mathrm{HIL}}, \mathrm{Par}_{\mathrm{H} 2 \mathrm{U}}$ and $\operatorname{Par}_{H 2 L}$, respectively. A further detail about both the generation of various lattice girders and the assignment of the design-related parameters in connection with both the proposed generating tool and ANSYS is found in Reference [17].

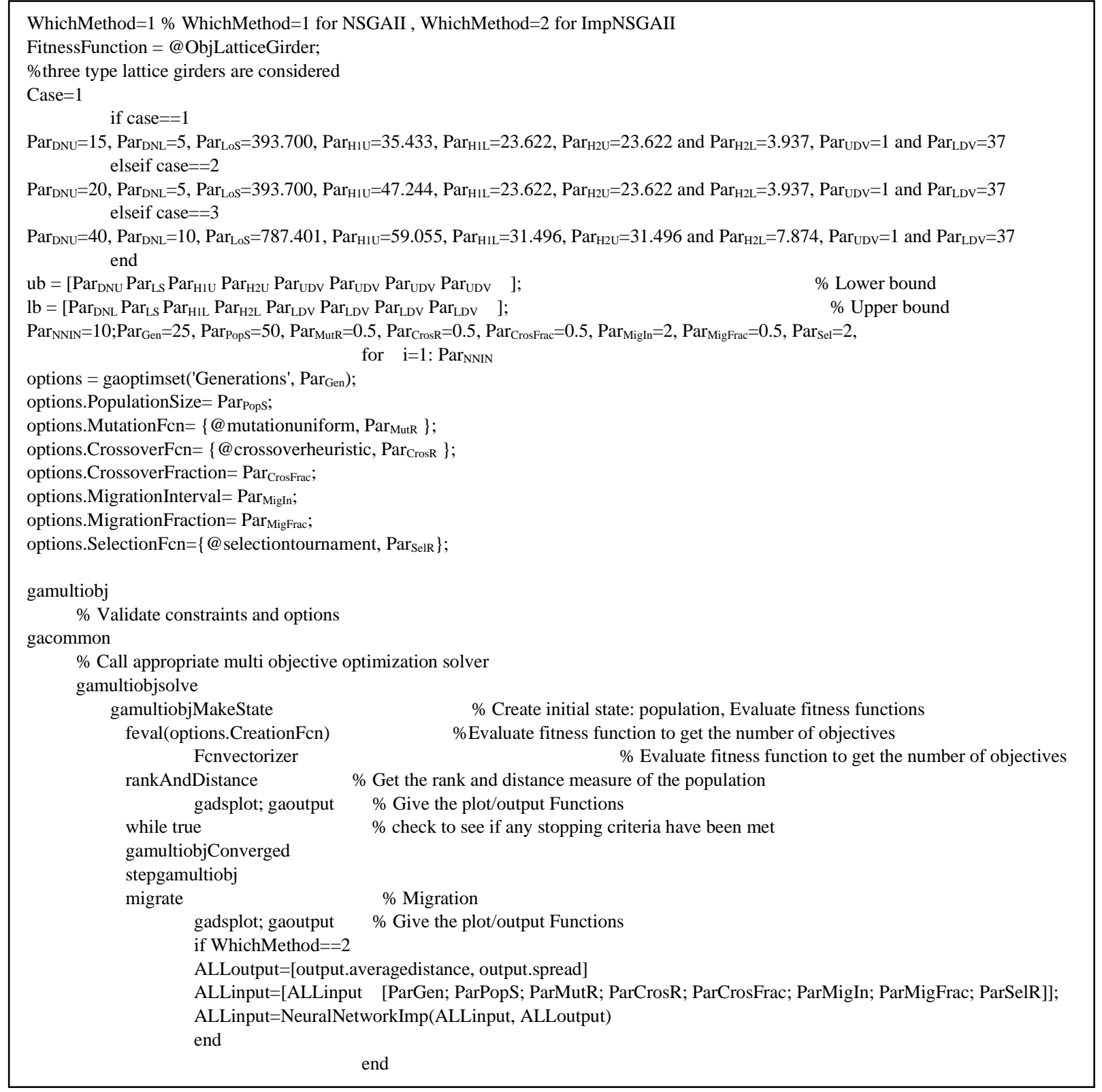

Fig. 1 A Matlab Script for ImpNSGAII and NSGAII

\section{An improved multi-objective optimization algorithm named Imp-}

\section{NSGAII}

It is mentioned that the nature-inspired multi-objective algorithms are mostly preferred in the design optimization of structural engineering applications due to their both higher search capabilities and simple search mechanisms. Particularly, the genetic algorithms (GAs), a branch of evolutionary algorithms has been accomplished to take more attention in the various engineering areas, particularly structural engineering applications [29-36]. Therefore, their fundamentals have been frequently utilized to arrange the basic elements of multiobjective optimization approaches.
The genetic algorithm approach completely mimics the main fundamentals of Darwian's evolutionary theory. Firstly, the decision (design) variables of optimization problem are appropriately coded in a chromosome. Then, the objective functions, which evaluate fitness (an indicator for the quality of chromosome), are determined depending on the preferences of designer. A number of individuals composed from chromosomes are gathered to form a population. Then, the individuals with a higher fineness values are selected, mutated and reproduced to form the next population. This generation process called evolution is stopped when a termination condition, for example a predefined generation number is fulfilled. This simple but effective search strategy of genetic algorithm has played a big role in the emergence of trend multi-objective optimization algorithms. The most popular one of these algorithms is NSGAII due to 
having a wide range usage in the various scientific fields [27]. The working principle of NSGAII is fundamentally based on the usage of genetic operators of GAs (crossover, mutation and selection) in the generation of promising individuals for next populations. Firstly, it is assumed that the individuals are collected in the different sparse and crowded regions of solution space. Then, the individuals are ranked considering the locations of these regions. In other words, crowding distance values of individuals are ranked taking into account of pareto ranking mechanism, which is responsible to assign a rank value began from 1 to the individuals. Thus, the best ranking individuals are selected and re-produced in order to generate the next populations. Therefore, the governing parameter values of genetic operators have a big impact on the computing capability of NSGAII. Although it is possible to determine the appropriate values of genetic operator parameters thereby trying their different combination sets, this approach will become not to be practical taking into account of its usage for a different design problem. In order to overcome this bottleneck, NSGAII is improved in a way of being utilized the neural network [17]. ImpNSGAII is basically based on adapting the parameter values of genetic operators throughout the evolutionary search thereby measuring the approximating and diversity degree of individuals in current population. The computing steps of ImpNSGAII are accordingly coded in MATLAB [37].

According to the pseudo code in Fig. 1, the fitness functions $f 1, f 2$ and $f 3$ coded in a separate toolbox "FitnessFunction" are computed considering the population $x^{0}$, which is arranged according to the limits of design variables $l b \& u b$ (see Eqns. (4-6)). Although the maximum design variable number "numberOfVariables" is taken as 8 (see Eqns. (4-6)), it is noted that the size of row matrix named $\operatorname{ParDN}$ is determined depending on the number of size type design variables. The current optimization procedure named NSGAII and coded in MATLAB [37] is essentially governed by a structure field, option. This structural filed contains both the genetic operators and their corresponding parameter values. Firstly, the toolbox "Gamultiobj", which contains the upper and lower limits of constraints along with the corresponding parameter names and values, is activated. Thus, the fitness functions are correspondingly computed considering the pre-defined design constraints. The toolbox "gamultiobjsolve", which automatically runs the two toolboxes "GamultiobjMakeState" and "stepgamultiobj" has a responsibility of computing the procedure of NSGAII. In fact, "GamultiobjMakeState", which is responsible to perform both the genetic operations such as selection, crossover, mutation and the quality measuring-related computation, is utilized in run of "stepgamultiobj".(see ROUTINE2 for a further detail about "GamultiobjMakeState" in Reference [17]). The toolbox "gamultiobjsolve" firstly runs the other toolbox "GamultiobjMakeState" for forming the beginning population in a way of utilizing options.CreationFen, calculate the fitness functions by "fcnvectorizer" and correspondingly order the fitness functions by "rankAndDistance". Following activation of "stepgamultiobj", the main generation is terminated depending on the value of parameter "options". Generations. It is noted that it is defined a number of termination options in the command "gamultiobjConverged". "Stepgamultiobj" is employed to execute the genetic operations (see ROUTINE1 in Reference [17]). It is noted that two toolboxes "gadsplot" and "gaoutput" can be utilized to plot a number of different outputs, following the execution of migration-related operations.

$$
x^{0}=[\underbrace{f i x\left(x_{1}^{0}\right),}_{\operatorname{Par}_{D N}} L S, x_{\operatorname{Par}_{H 1} \text { and } \operatorname{Par}_{H 2}^{0}, x_{3}^{0}}^{f i x\left(x_{4}^{0}\right), f i x\left(x_{5}^{0}\right), f i x\left(x_{6}^{0}\right), f i x\left(x_{7}^{0}\right)}]
$$

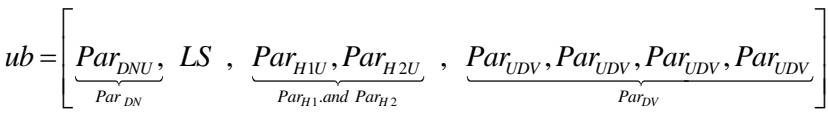

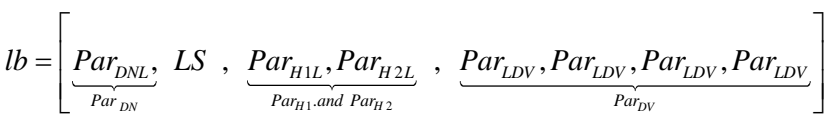

The governing parameters of both ImpNSGAII and NSAGAII are defined in the structure field "options" as "options.Genarations" Par, "options. PopulationSize" Par $r_{2}$, "options. MutationFcn \{@mutationuniform.\}" Par 3 , “options. CrossoverFcn \{@ crossoverheuristic.\}" Par 4 , "options. CrossoverFraction" Par, "options. MigrationInterval" Par 6 , "options. MigrationFraction" Par 7 , "options. SelectionFcn\{@selectiontournament.\}" Par

Table 1

\begin{tabular}{|c|c|c|c|c|c|c|c|c|c|c|}
\hline \multirow[b]{2}{*}{ Governing Parameters } & \multicolumn{10}{|c|}{$\operatorname{Par}_{\text {NNIN }}(\operatorname{ImpNSGAII)}$} \\
\hline & 1 & 2 & 3 & 4 & 5 & 6 & 7 & 8 & 9 & 10 \\
\hline $\operatorname{Par}_{1}$ & 22 & 3 & 20 & 19 & 21 & 16 & 15 & 11 & 17 & 4 \\
\hline $\mathrm{Par}_{2}$ & 36 & 42 & 34 & 34 & 30 & 29 & 30 & 26 & 15 & 16 \\
\hline $\mathrm{Par}_{3}$ & 0.7099 & 0.4629 & 0.7059 & 0.6367 & 0.5906 & 0.4630 & 0.4550 & 0.4258 & 0.9034 & 0.4446 \\
\hline $\mathrm{Par}_{4}$ & 0.4990 & 0.3951 & 0.7810 & 0.4712 & 0.2297 & 0.8838 & 0.9060 & 0.1529 & 0.2113 & 0.3037 \\
\hline Par $_{5}$ & 0.7356 & 0.7848 & 0.5574 & 0.7881 & 0.7740 & 0.2621 & 0.3183 & 0.6292 & 0.2972 & 0.4280 \\
\hline Par 6 & 2 & 4 & 3 & 3 & 4 & 3 & 4 & 2 & 2 & 5 \\
\hline $\operatorname{Par}_{7}$ & 0.3316 & 0.8239 & 0.9441 & 0.9397 & 0.9543 & 0.5917 & 0.2362 & 0.6962 & 0.5181 & 0.8556 \\
\hline Pars $_{8}$ & 0.5863 & 0.4983 & 0.9625 & 0.1392 & 0.4255 & 0.8895 & 0.6899 & 0.4745 & 0.4170 & 0.6502 \\
\hline
\end{tabular}

The Governing Parameter Values of ImpNSGAII and NSGAII

Governing Parameters

$\begin{array}{lc}\text { Par }_{1} & 100 \\ \text { Par }_{2} & 50 \\ \text { Par }_{3} & 0.5 \\ \text { Par }_{4} & 0.5 \\ \text { Par }_{5} & 0.5 \\ \text { Par }_{6} & 5 \\ \text { Par }_{7} & 0.5 \\ \text { Par } & \end{array}$

See the definitions of abbreviations for the governing parameters in Section 3

\section{Discussion of results}

In this study, the member and joint-related strength design constraints are taken from API RP2A-LRFD specification [28]. The influences of MRDC and JRDC on the optimality qualities of designs are investigated. Furthermore, the computing capability of ImpNSGAII is also compared by NSGAII algorithm including the other optimization approaches proposed in Literature. A bench- mark lattice girder and a general lattice girder, configuration of which are automatically generated depending on a user-defined loading adjustment and spanning length are devised as the application design examples. In fact, these design problems were also optimized considering only MRDC in Reference [17]. Thus, it was shown that the optimal configurations of lattice girders simultaneously satisfied the economy, load-resistance and serviceability-related design conditions. It is noted that the load-resistance capability of lattice girders is determined according to the member forces. 
Table 2

Extreme Optimal Designs (OD) and Corresponding Design (D) Values (Design Example 1)

\begin{tabular}{|c|c|c|c|c|c|c|c|c|c|c|c|c|c|c|c|c|c|}
\hline & \multicolumn{17}{|c|}{ Size Type Design Variables ${ }^{a 1}$} \\
\hline & $\bar{a}$ & ธิ & $\hat{\omega}$ & 苞 & $\ddot{a}$ & ฉ̊ & $\hat{\theta}$ & $\stackrel{\circ}{\circ}$ & คิ & $\stackrel{\circ}{a}$ & $\overline{\bar{D}}$ & $\frac{2}{0}$ & $\frac{m}{a}$ & $\frac{\Delta}{\Delta}$ & $\frac{n}{n}$ & $\frac{0}{a}$ & $\bar{a}$ \\
\hline $\begin{array}{l}\text { OD1 } \\
\text { (MW) }\end{array}$ & 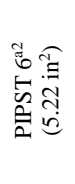 & 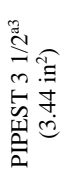 & 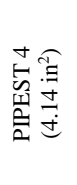 & 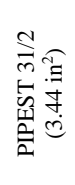 & 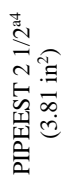 & 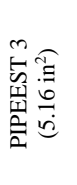 & 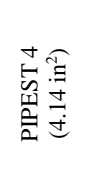 & 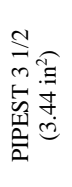 & 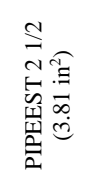 & 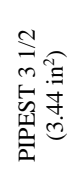 & 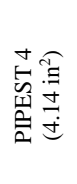 & 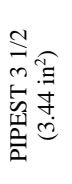 & 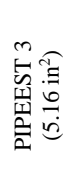 & 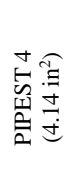 & 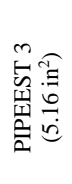 & 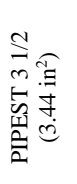 & 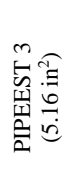 \\
\hline $\begin{array}{l}\text { OD2 } \\
\text { (MJD) }\end{array}$ & 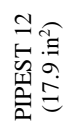 & 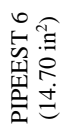 & 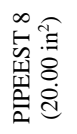 & 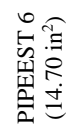 & 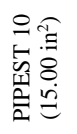 & 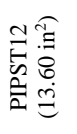 & 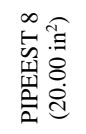 & 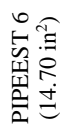 & 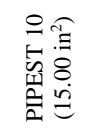 & 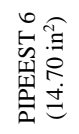 & 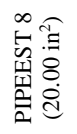 & 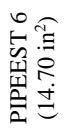 & 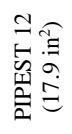 & 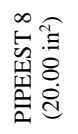 & 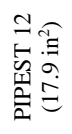 & 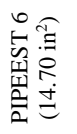 & 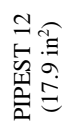 \\
\hline $\begin{array}{l}\text { OD3 } \\
\text { (MEF) }\end{array}$ & 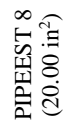 & 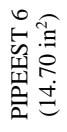 & 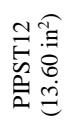 & 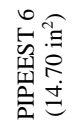 & 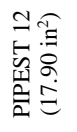 & 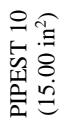 & 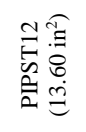 & 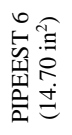 & 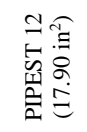 & 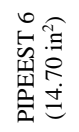 & 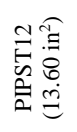 & 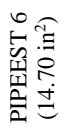 & 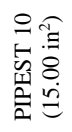 & 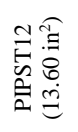 & 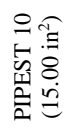 & 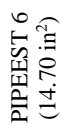 & 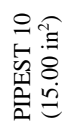 \\
\hline $\begin{array}{l}\text { Ref. [38] } \\
\quad\left(\mathrm{in}^{2}\right)\end{array}$ & $\begin{array}{l}\vec{D} \\
\infty \\
\underline{n}\end{array}$ & $\frac{\infty}{\circ}$ & $\stackrel{\circ}{\circ}$ & $\frac{8}{0}$ & $\frac{i}{\infty}$ & $\begin{array}{l}5 \\
0 \\
n \\
n\end{array}$ & ָे & $\frac{8}{0}$ & 商 & $\frac{8}{0}$ & 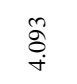 & $\frac{8}{0}$ & 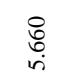 & $\underset{\check{8}}{\overline{8}}$ & $\begin{array}{l}0 \\
6 \\
i \\
i\end{array}$ & $\frac{8}{0}$ & $\begin{array}{l}\text { D̃ } \\
\infty \\
n \\
n\end{array}$ \\
\hline $\begin{array}{l}\text { Ref. [39] } \\
\quad\left(\mathrm{in}^{2}\right)\end{array}$ & ڤ్ & $\frac{8}{0}$ & 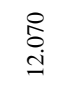 & $\frac{8}{0}$ & $\underset{\infty}{\infty}$ & $\begin{array}{l}\text { ర్ } \\
n \\
n \\
n\end{array}$ & $\stackrel{\varrho}{\sigma}$ & $\frac{8}{\stackrel{8}{0}}$ & $\stackrel{n}{\stackrel{2}{r}}$ & $\frac{8}{9}$ & 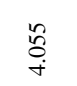 & $\frac{8}{0}$ & $\underset{n}{n}$ & 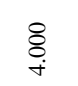 & $\begin{array}{l}\infty \\
n \\
n \\
n \\
n\end{array}$ & $\frac{8}{0}$ & $\begin{array}{l}\hat{\hat{n}} \\
\text { in }\end{array}$ \\
\hline \multirow[t]{2}{*}{$\begin{array}{l}\text { Ref. [40] } \\
\quad\left(\mathrm{in}^{2}\right)\end{array}$} & $\begin{array}{l}\stackrel{0}{\infty} \\
\qquad \\
\end{array}$ & $\frac{3}{0}$ & 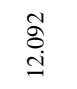 & $\frac{8}{6}$ & $\underset{\infty}{\infty}$ & 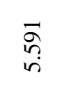 & $\stackrel{n}{\frac{n}{a}}$ & $\frac{8}{0}$ & $\frac{2}{2}$ & $\frac{8}{0}$ & $\stackrel{゚}{\stackrel{\circ}{0}}$ & $\frac{8}{6}$ & $\begin{array}{l}\stackrel{R}{6} \\
\dot{r}\end{array}$ & 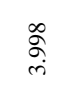 & 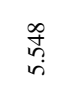 & $\frac{\wp}{0}$ & $\begin{array}{l}n \\
n \\
n\end{array}$ \\
\hline & \multicolumn{5}{|c|}{ Entire Weight } & \multicolumn{4}{|c|}{ Joint Displacement } & \multicolumn{6}{|c|}{ Maximum Member Force and Stress } & \multicolumn{2}{|c|}{$\begin{array}{c}\text { Load Step } \\
\text { Number }\end{array}$} \\
\hline $\begin{array}{l}\text { Des } 1 \\
(M W)\end{array}$ & \multicolumn{5}{|c|}{$\begin{array}{l}2515.895 \mathrm{lb}^{\mathrm{a} 1} \\
1539.907 \mathrm{lb}^{a 5}\end{array}$} & \multicolumn{4}{|c|}{$\begin{array}{l}1.217 \mathrm{in}^{\mathrm{a} 1} \\
1.492 \mathrm{in}^{a 5}\end{array}$} & \multicolumn{6}{|c|}{$\begin{array}{c}240.033^{\mathrm{a} 1} \text { and } 25.87 \mathrm{ksi}^{\mathrm{a} 1} \\
239.958 \text { and } 29.83 \mathrm{ksi}^{a 5}\end{array}$} & \multicolumn{2}{|c|}{$\begin{array}{l}2^{\mathrm{a} 1} \\
2^{a 5}\end{array}$} \\
\hline Des2 $(M J D)$ & \multicolumn{5}{|c|}{$\begin{array}{l}9416.272 \mathrm{lb} \\
6386.020 \mathrm{lb}\end{array}$} & & $\begin{array}{l}0.28 \\
1.9\end{array}$ & & & \multicolumn{6}{|c|}{$\begin{array}{l}240.000 \text { and } 6.200 \mathrm{ksi} \\
1239.191 \text { and } 47.89 \mathrm{ksi}\end{array}$} & \multicolumn{2}{|c|}{3} \\
\hline $\operatorname{Des} 3(M E F)$ & \multicolumn{5}{|c|}{$9134.793 \mathrm{lb}$} & & $\begin{array}{l}1.6 \\
1.5\end{array}$ & & & \multicolumn{3}{|c|}{1240.472 and $36.80 \mathrm{ksi}$} & & & & \multicolumn{2}{|c|}{$\begin{array}{l}3 \\
3\end{array}$} \\
\hline Ref. [38] & \multicolumn{5}{|c|}{$2580.81 \mathrm{lb}$} & \multicolumn{4}{|c|}{ N/A } & \multicolumn{6}{|c|}{ N/A } & \multicolumn{2}{|c|}{ N/A } \\
\hline Ref. [39] & \multicolumn{5}{|c|}{$2581.89 \mathrm{lb}$} & \multicolumn{4}{|c|}{ N/A } & \multicolumn{6}{|c|}{ N/A } & \multicolumn{2}{|c|}{ N/A } \\
\hline Ref. [40] & \multicolumn{5}{|c|}{$2581.94 \mathrm{lb}$} & \multicolumn{4}{|c|}{ N/A } & \multicolumn{6}{|c|}{ N/A } & \multicolumn{2}{|c|}{ N/A } \\
\hline $\begin{array}{l}\text { a1: According } \\
\text { a2: PIPST (Sta } \\
\text { a3: PIPEST (E } \\
\text { a4: PIPEEST } \\
\text { a5: According }\end{array}$ & $\begin{array}{l}\text { Displac } \\
\text { lard Tub } \\
\text { a Stron } \\
\text { ouble-Ex } \\
\text { Displac }\end{array}$ & $\begin{array}{l}\text { ent, M } \\
\text { Ir Cross } \\
\text { ubular } \\
\text { Strons } \\
\text { ent, M }\end{array}$ & $\begin{array}{l}\text { ber and } \\
\text { ections) } \\
\text { oss-sect } \\
\text { ubular ( } \\
\text { ber-relat }\end{array}$ & $\begin{array}{l}\text { ns) } \\
\text { oss-sec } \\
\text { d Desi }\end{array}$ & Design & & & & $\begin{array}{l}\text { MW: Mi } \\
\text { MJD: Mi } \\
\text { MMF: }\end{array}$ & $\begin{array}{l}\text { mum W } \\
\text { mum Jo } \\
\text { ximum }\end{array}$ & $\begin{array}{l}\text { ght Valu } \\
\text { t Displa } \\
\text { ember F }\end{array}$ & $\begin{array}{l}\text { ment } \mathrm{Va} \\
\text { e Value }\end{array}$ & & & & & \\
\hline
\end{tabular}

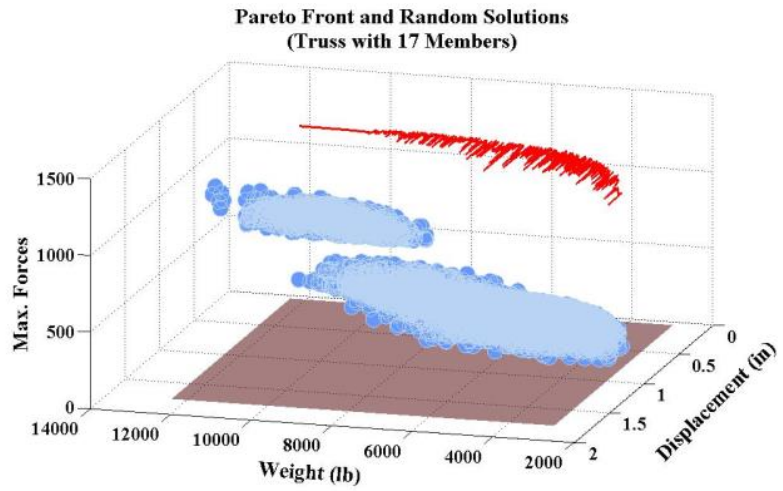

Fig. 2 True Pareto front Design Example 1

\subsection{A benchmark lattice girder design}

This structural system is subject to a joint load of $100 \mathrm{kipf}$ on the joint number 9. It is defined as Design Example 1. The optimal design this simple lattice girder was firstly carried out in References [38-40].

True pareto front with a red color obtained using JRDC\&MRDC is presented Fig. 2. The governing parameters of relatively successful ImpNSGAII and NSGAII is presented in Table 1.

In order to make a further investigation into the influence of JRDC on the optimality quality of designs obtained, some extreme designs are tabulated in Table 2. Considering Table 2, the minimum values of entire weight obtained using JRDC are higher than ones obtained using MRDC. It is clear that an inclusion of JRDC into the design constraints causes to increase the construction cost of optimal design.

This claim is also confirmed considering Fig. (3-5). Considering Fig. (3-5), it is shown that the termination number of load steps is almost 3 for both MRDC and JRDC. But, the unity values of JRDC are higher than the MRDC (see Fig. 
$3 \mathrm{~g}$ and $5 \mathrm{~g}$ ). Thus, it is said that the influence of JRDC on the quality of optimal design has a big impact compared to MRDC.

When the unity values in Fig. (3-5) are considered, it is observed two design constraints named axial compression\&bending buckling and joint yield has a big effect on the optimality quality of extreme designs compared MRDC due to their higher values (see Fig. 3c,4c,5c,3g, 4g and 5g). In case of using the JRDC and MRDC at the same time, it is also shown that the axial forces have a relatively higher importance on the optimality quality of extreme designs due to their higher values (see Fig. 3a,3c,4a,4c,5a and 5c).
Moreover, the variation of their unity values with respect to the member (element) and joint (node) number is also sketched using bar-charts in Fig. 6. Considering Fig. 6, it is seen that the load step numbers indicated the termination of nonlinear structural responses are identical for both MRDC and JRDC.

The important reason behind the similarity between results obtained is the fixed geometry and framing configuration of benchmark design example with 17 members. It is expected that a change in the framing configuration of benchmark lattice girder leads to an activation of different JRDC and MRDC. This expected result will be examined in the next design example with varying geometry and framing configurations.

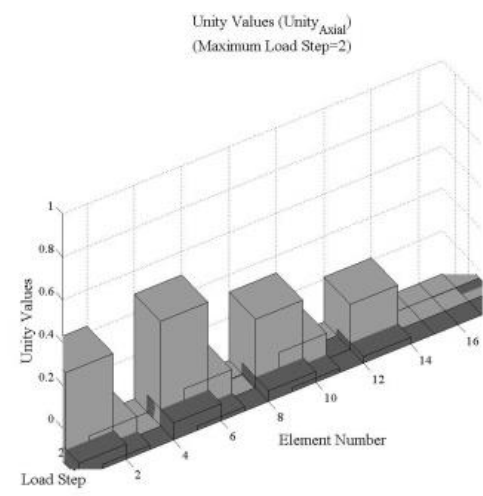

(a)

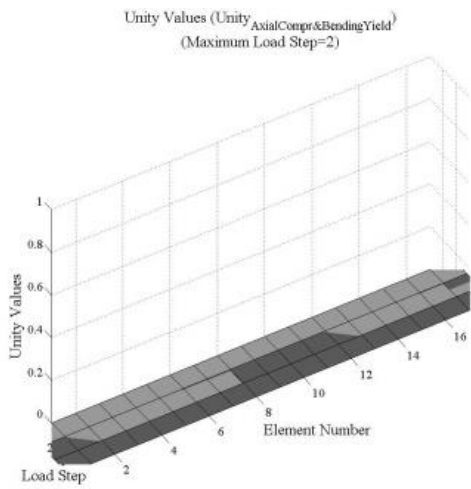

(d)

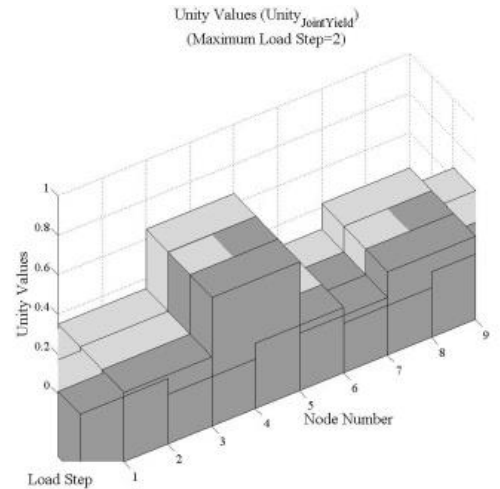

(g)

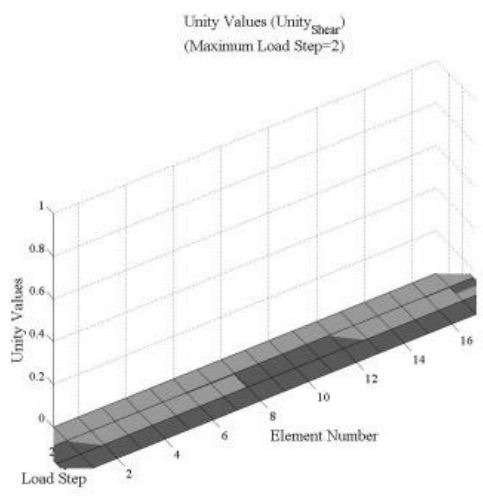

(b)

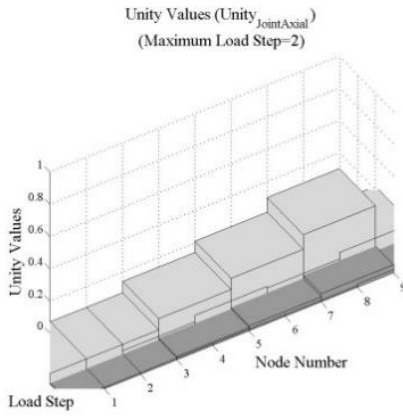

(e)

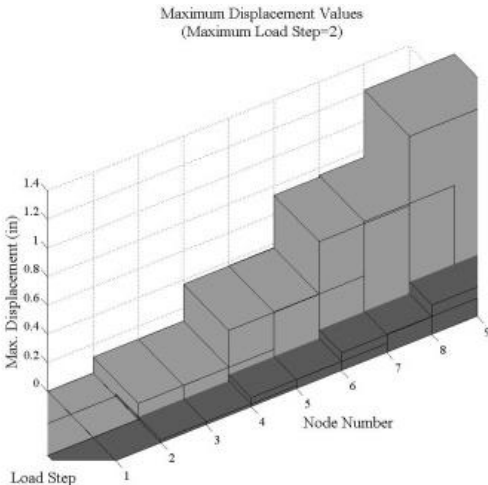

(h)

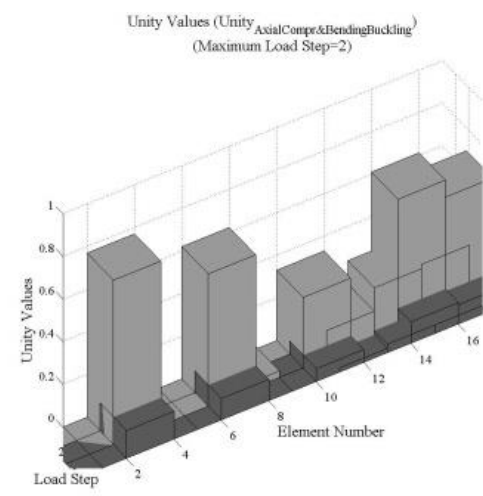

(c)

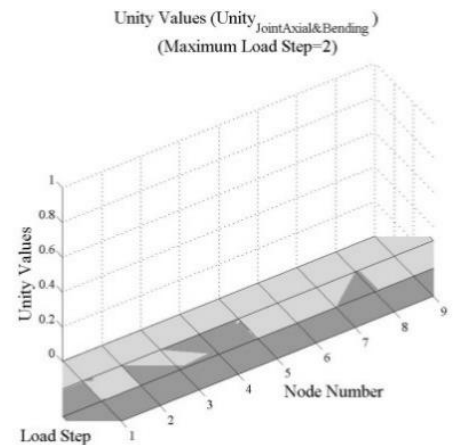

(f)

Fig. 3 Variation in The Unity Values of MRDC (a-d), JRDC (e-g), Join Displacements (h) According to Load Steps Obtained for Minimum Weight (see Design Example 1in Table 2) 


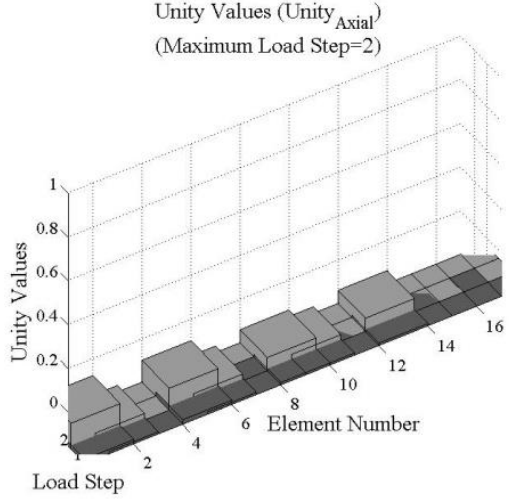

(a)

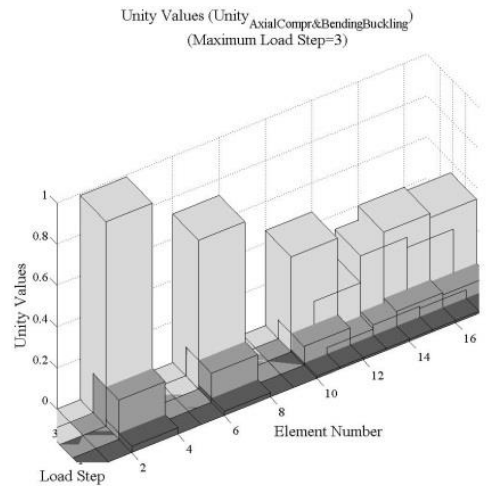

(c)

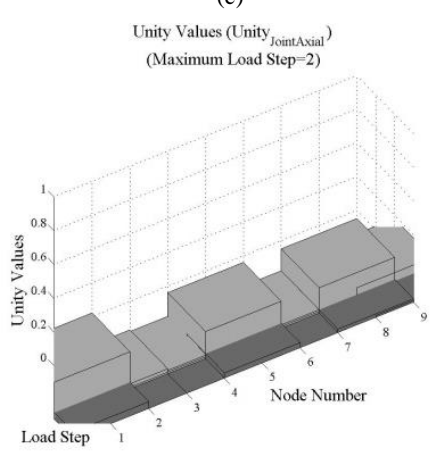

(e)

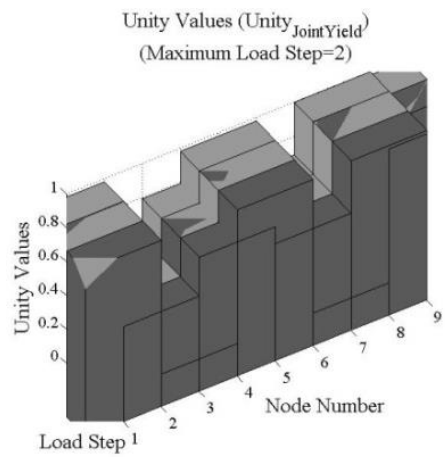

(g)

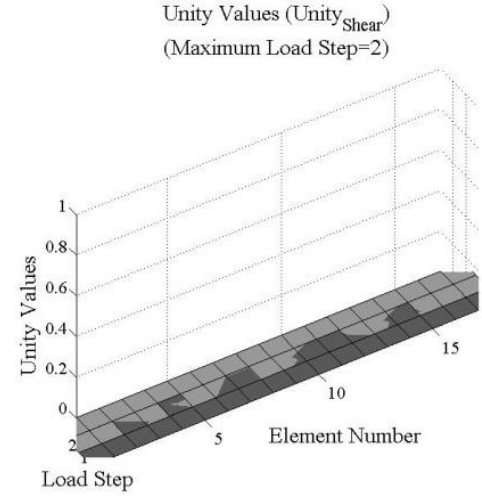

(b)

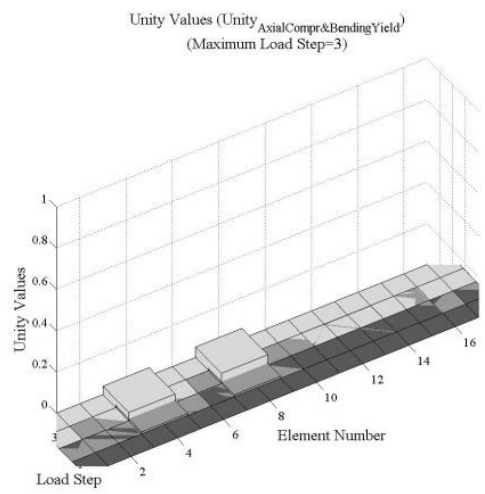

(d)

Unity Values (Unity JointAxiale Bending $_{\text {) }}$

(Maximum Load Step=2)

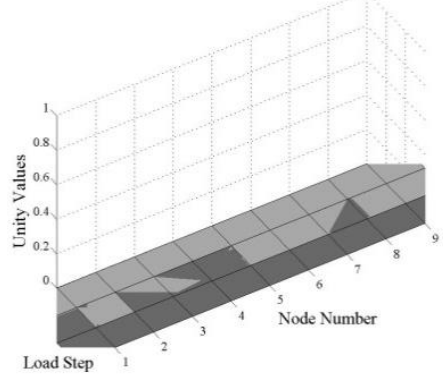

(f)

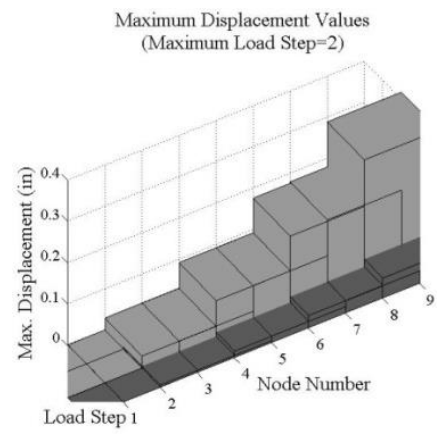

(h)

Fig. 4 Variation in The Unity Values of MRDC (a-d), JRDC (e-g), Join Displacements (h) According to Load Steps Obtained for Minimum Displacement (see Design Example 1in Table 2) 


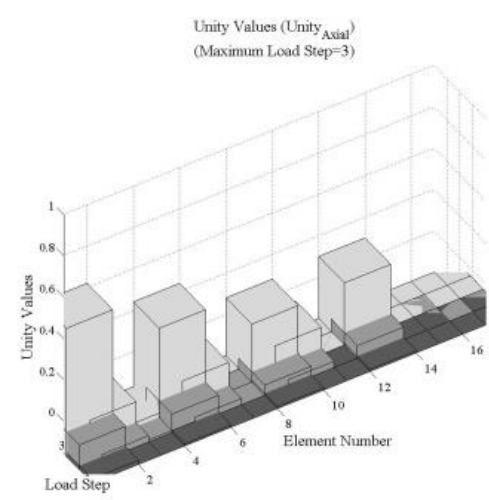

(a)

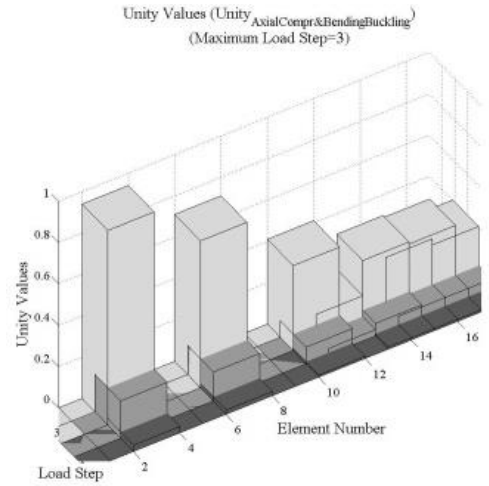

(c)

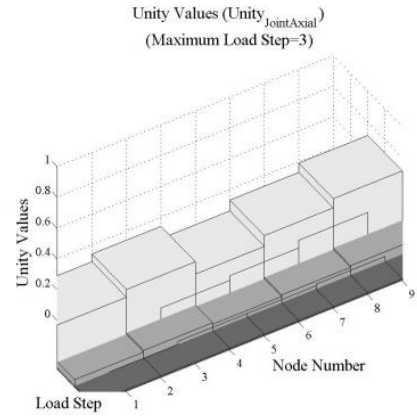

(e)

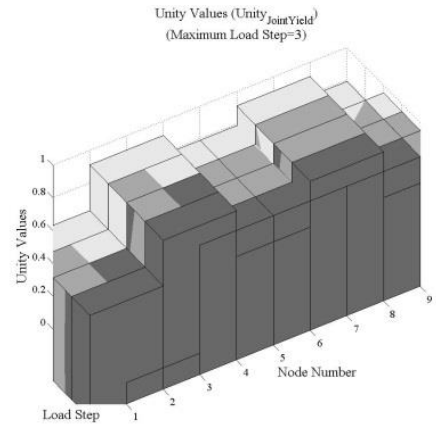

(g)

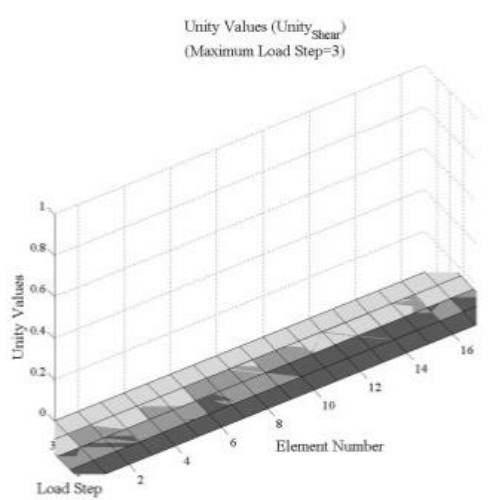

(b)

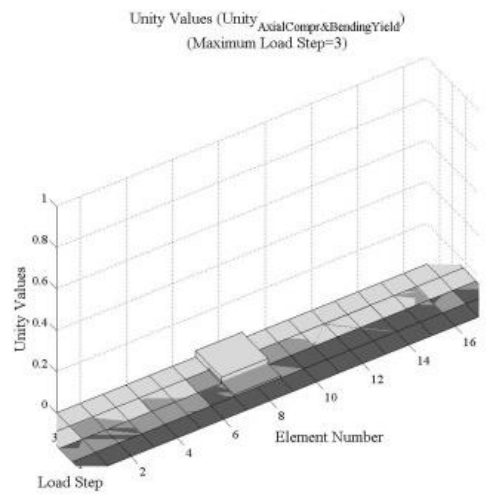

(d)

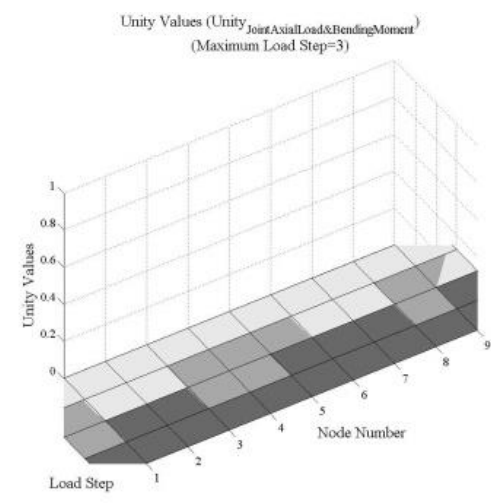

(f)

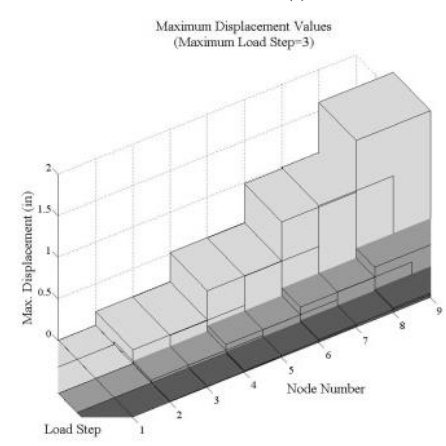

(h)

Fig. 5 Variation in The Unity Values of MRDC (a-d), JRDC (e-g), Join Displacements (h) According to Load Steps Obtained for Maximum Critical Load (see Design Example 1 in Table 


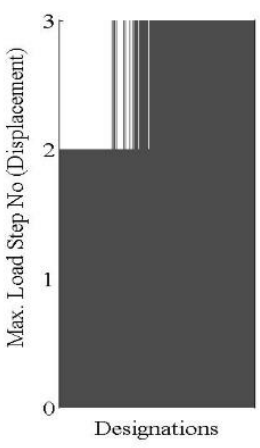

(a)

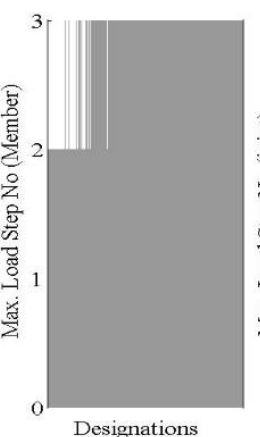

(b)

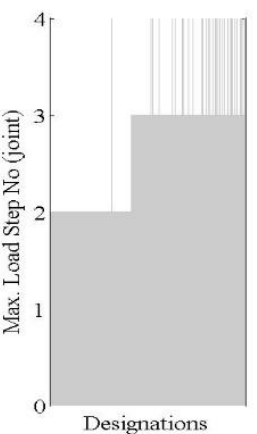

(c)
Fig. 6 The Maximum Load Step Numbers (see Table 2)

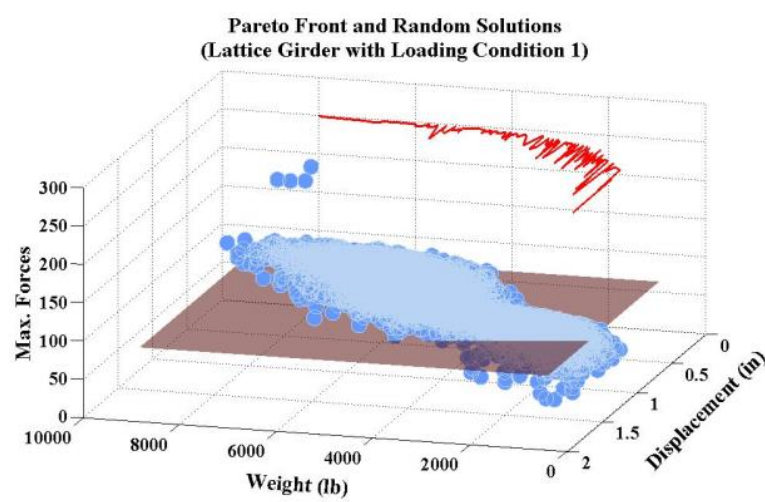

(a)

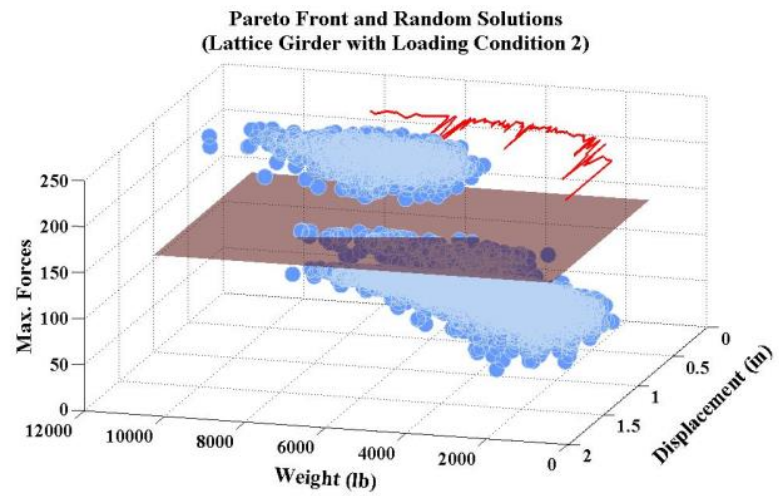

(b)

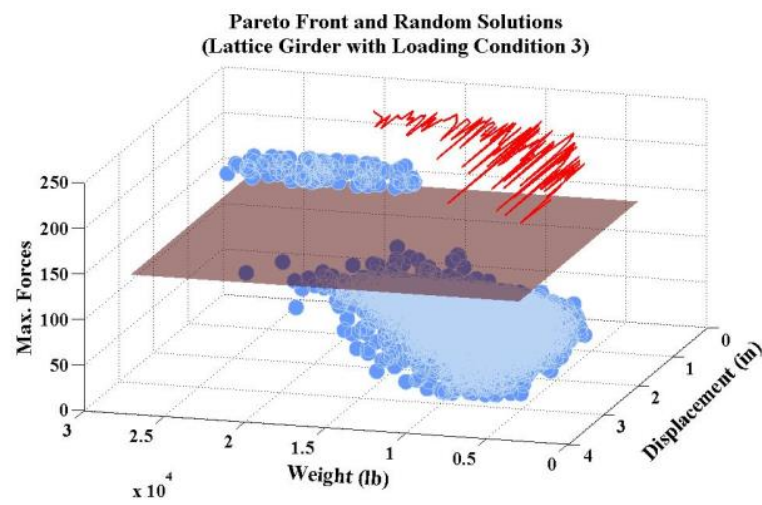

(c)

Fig.7 True Pareto Fronts for Lattice Girder1 (a) and Lattice Girder2 (b) and Lattice

Girder3 (a)

\subsection{A general lattice girder}

In this design example, a lattice girder with three spanning lengths and loading adjustments are automatically generated at the design stage and defined as Design Example 2 (see Table 3). Hence, it will be possible to determine the relative effectiveness of JRDC and MRDC on the quality of optimal design. For this purpose, the upper joints of lattice girder, numbers of which is obtained assuming as (length of span $L S$ /division number $\operatorname{Par}_{\mathrm{DN}}$ ). The design complexity of lattice girder is sequentially increased in a way of applying three different combination cases of total load and spanning length to the lattice girder automatically generated (see Table 3). Hence, the influence of JRDC on the optimality quality of lattice girder designs is also investigated depending on the severe loading conditions and spanning lengths.

True pareto fronts obtained using JRDC\&MRDC are presented Fig. 7 for three different loading\&spanning cases. The governing parameters of relatively successful ImpNSGAII and NSGAII is presented in Table 4.

The results obtained from the design optimization of lattice girder, which has an increasing design complexity (see Tables (5-6)) are firstly categorized considering the proposed design unities along with the three different loading\&spanning cases and figured in Fig. (8-14) instead of presenting all of the unity values as in section of benchmark lattice girder design. Then, these results are summarized in the following two different grouping (see Table 7). Moreover, the variation in the load steps with respect to the multiple objective functions considering the optimal designs obtained from the execution of proposed optimization tool is also included (see Fig. 15).

The influence of JRDC on the optimality quality of optimal designs is investigated in conjunction with MRDC. The variation in MRDC and JRDC unities are presented in Fig. (8-14) The extreme optimal designs are reported for three cases of lattice girder in Tables (5-6) and also summarized in Table 7 considering the critical values of related unities. It is noted that the optimal designs in Table 6 corresponds to the feasible design solutions corresponding to the higher load value. The tabulated data in Tables (5-6) contains the resulted size type design variables $D 1-D 4$, shape type design variables $\operatorname{Par}_{H 1}, P{ }_{H 2}$, topology type design variables Par $_{D N}$ of lattice girders including their objective function values and corresponding framing representations. Furthermore, the each of these extreme optimal designs is sketched using bar charts to illustrate the varying values of JRDC and MRDC-related unities with respect to the load steps outcome from the nonlinear structural analysis (see Fig. 15).

It is mentioned that the cross-sectional properties for the members of lattice girders assigned in a way of using the steel profiles which contains 37 different circular-hollow-shaped cross-sections. These circular-hollow-shaped cross-sections are categorized in three different type class: "standard", "extra strong" and "double extra strong". In fact, this categorization is made depending on an increase in the cross-sectional thickness and related cross-sectional properties.

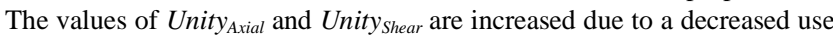
of diagonal members in the construction of tubular lattice girder, which have a responsibility to decrease both the shear and the axial forces of each members connected to a single node. In fact, the other negative effect is arisen from the use of steel profiles with standard type tubular cross-sections instead of double extra and extra strong ones (see Fig. (8-9) and Tables (5-6)). In general, the weight minimization is not only one of the main reasons behind the higher values of these unities, but the maximization of forces has also a relative responsibility (see Table 7).

The increased assignment of steel profiles with the standard type tubular cross-sections to the member of lattice girder causes to increase the values of Unity $_{\text {AxialCompr\&BendingBuckling }}$ and Unity AxialCompr\&BendingYield $_{\text {due to the decrease in the }}$ two profile cross-sectional properties, the diameter and the plastic section modulus (see Fig. (10-11) and Tables (5-6)). In general, the weight minimization has a responsibility of increasing the values of these unities (see Table 7).

The use of steel profiles with decreased diameter and thickness as a chord member rather than a brace member causes to an increase in the values of Unity $y_{\text {JointAxial }}$ and Unity JointAxial\&Bending $($ see Fig. (12-13) and Tables (5-6)). The maximization of member forces has a main responsibility in the increase of these unities. But it is also noted that this increase is also relatively arisen from the weight minimization (see Table 7).

An increase in the middle height of lattice girder along with the use of decreased cross-sectional thickness for the chord members, which is indicated by $\operatorname{Par}_{H 2}$, causes to elevate the values of Unity ${ }_{\text {JointYield }}$ (see Fig. 14 and Table 7-8). Whereas the minimization of joint displacement generally leads to an increase in the value of Unity JointYield, the weight minimization also increases this unity value (see Table 7).

The contribution of JRDC to the optimal lattice girder design is also clarified by examining the maximum load step numbers (see Fig. 7). Considering Fig. 7, it is seen that the load steps numbers corresponding to both JRDC and MRDC are equally terminated. This result implies that the inclusion of JRDC into the current design constraints regarding to MRDC affects the quality of optimal designs. Furthermore, the obvious evidence that supports this claim has already presented with the lower values of maximum member forces obtained using JRDC with respect to the higher maximum member forces obtained using the MRDC (see Tables (5-6)). 
Table 3

The Proposed Lattice Girder Patterns and Corresponding Values of Their Design Variables

\begin{tabular}{|c|c|c|c|}
\hline & Lattice Girder 1 & Lattice Girder 2 & Lattice Girder 3 \\
\hline \multicolumn{4}{|c|}{ Arrangements for Spanning, Loading and Material Conditions } \\
\hline \multicolumn{4}{|c|}{ Assignments to Describe The General Structural System } \\
\hline Total Load Value & 70 kipf & 140 kipf & $150 \mathrm{kipf}$ \\
\hline Length of Span & $393.70 \mathrm{in.}$ & 393.70 in. & 787.40 in. \\
\hline Maximum Node Deflection. & \multicolumn{3}{|l|}{3.94 in } \\
\hline Material Yield Value & \multicolumn{3}{|l|}{$36 \mathrm{ksi}$} \\
\hline Elasticity Module & \multicolumn{3}{|l|}{$29732 \mathrm{ksi}$} \\
\hline \multicolumn{4}{|c|}{ Arrangements for Size Type Parameter $\operatorname{Par}_{\mathrm{ND}}$} \\
\hline $\operatorname{Par}_{\mathrm{ND}}$ & 4 & 4 & 4 \\
\hline $\operatorname{Par}_{\text {UDV }}$ & 37 & 37 & 37 \\
\hline $\operatorname{Par}_{\text {LDV }}$ & 1 & 1 & 1 \\
\hline \multicolumn{4}{|c|}{ Arrangements for Topology Type Parameter Par $_{\mathrm{ND}}$} \\
\hline Par $_{\text {UDN }}$ & 15 & 20 & 40 \\
\hline $\operatorname{Par}_{\text {LDN }}$ & 5 & 5 & 10 \\
\hline \multicolumn{4}{|c|}{ Arrangements for Shape Type Parameters $\operatorname{Par}_{\mathrm{H} 1}$ and $\mathrm{Par}_{\mathrm{H} 2}$} \\
\hline $\mathrm{Par}_{\mathrm{UH} 2}$ & 35.433 in. & 47.244 in. & 59.055 in. \\
\hline $\mathrm{Par}_{\mathrm{LH} 2}$ & 23.622 in. & 23.622 in. & 31.496 in. \\
\hline $\mathrm{Par}_{\mathrm{UH} 1}$ & 23.622 in. & 23.622 in. & 31.496 in. \\
\hline $\mathrm{Par}_{\mathrm{LH} 1}$ & 3.937 in. & 3.937 in. & 7.874 in. \\
\hline
\end{tabular}

Table 4

The Governing Parameter Values of ImpNSGAII and NSGAII

\begin{tabular}{|c|c|c|c|c|c|c|c|c|c|c|c|}
\hline & \multirow[b]{2}{*}{ Governing Parameters } & \multicolumn{10}{|c|}{$\operatorname{Par}_{\text {NNIN }}$ (ImpNSGAII) } \\
\hline & & 1 & 2 & 3 & 4 & 5 & 6 & 7 & 8 & 9 & 10 \\
\hline Par $_{I}$ & & 11 & 2 & 13 & 23 & 20 & 6 & 2 & 17 & 19 & 4 \\
\hline Par $_{2}$ & & 26 & 30 & 45 & 35 & 23 & 37 & 45 & 49 & 25 & 38 \\
\hline $\mathrm{Par}_{3}$ & & 0.9395 & 0.5844 & 0.5096 & 0.9253 & 0.2656 & 0.8872 & 0.4593 & 0.2620 & 0.6779 & 0.7484 \\
\hline $\mathrm{Par}_{4}$ & & 0.5498 & 0.3828 & 0.2768 & 0.7763 & 0.2533 & 0.6058 & 0.1762 & 0.8198 & 0.5180 & 0.2030 \\
\hline Par5 & & 0.4906 & 0.2777 & 0.7328 & 0.1986 & 0.6586 & 0.3603 & 0.5689 & 0.2499 & 0.4431 & 0.4590 \\
\hline Par $_{6}$ & & 2 & 2 & 3 & 3 & 3 & 4 & 3 & 3 & 5 & 2 \\
\hline $\operatorname{Par}_{7}$ & & 0.3672 & 0.5450 & 0.3270 & 0.9784 & 0.2720 & 0.4395 & 0.4759 & 0.1527 & 0.7711 & 0.6486 \\
\hline \multirow{2}{*}{\multicolumn{2}{|c|}{ Par }} & 0.6337 & 0.5551 & 0.4679 & 0.4774 & 0.4204 & 0.1606 & 0.4266 & 0.9318 & 0.3035 & 0.8082 \\
\hline & & \multicolumn{10}{|c|}{$\operatorname{Par}_{\text {NNIN }}=1$ (NSGAII) } \\
\hline & Governing Parameters & \multicolumn{10}{|c|}{1} \\
\hline Par $_{I}$ & & \multicolumn{10}{|c|}{100} \\
\hline $\mathrm{Par}_{2}$ & & \multicolumn{10}{|c|}{50} \\
\hline $\mathrm{Par}_{3}$ & & \multicolumn{10}{|c|}{0.5} \\
\hline $\mathrm{Par}_{4}$ & & \multicolumn{10}{|c|}{0.5} \\
\hline Par $_{5}$ & & \multicolumn{10}{|c|}{0.5} \\
\hline Par6 & & \multicolumn{10}{|c|}{5} \\
\hline $\mathrm{Par}_{7}$ & & \multicolumn{10}{|c|}{0.5} \\
\hline Pars & & \multicolumn{10}{|c|}{0.5} \\
\hline
\end{tabular}


Table 5

Extreme Optimal Design (OD) Values (Design Example 2)

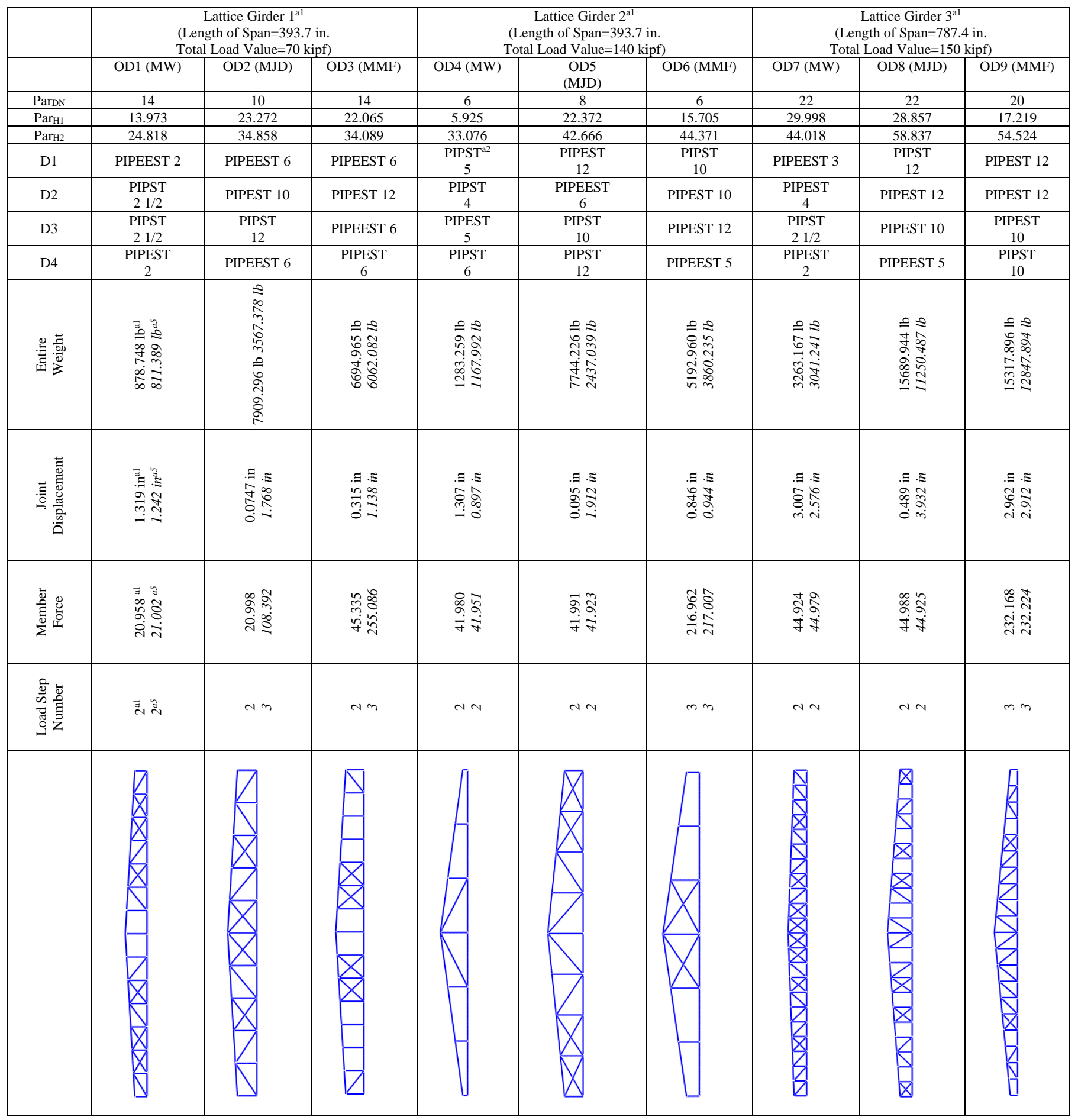

See the definitions for sub\&superscripts and other abbreviations in Table 2 
Table 6

Extreme Optimal Design (OD) Values (Design Example 2)

\begin{tabular}{|c|c|c|c|c|c|c|c|c|c|}
\hline & \multicolumn{3}{|c|}{$\begin{array}{c}\text { Lattice Girder }^{\text {al }} \\
\text { (Length of Span=393.7 in. } \\
\text { Total Load Value=70 kipf) }\end{array}$} & \multicolumn{3}{|c|}{$\begin{array}{c}\text { Lattice Girder } 2^{\text {al }} \\
\text { (Length of Span=393.7 in. } \\
\text { Total Load Value=140 kipf) }\end{array}$} & \multicolumn{3}{|c|}{$\begin{array}{c}\text { Lattice Girder } 3^{\text {al }} \\
\text { (Length of Span=787.4 in. } \\
\text { Total Load Value=150 kipf) }\end{array}$} \\
\hline & OD10 (MW) & OD11 (MJD) & OD12 (MMF) & OD13 (MW) & OD14 (MJD) & OD15 (MMF) & OD16 (MW) & OD17 (MJD) & OD18 (MMF) \\
\hline Par $_{\mathrm{DN}}$ & $6^{a 1}$ & 6 & 14 & 6 & 6 & 6 & 16 & 30 & 20 \\
\hline ParH1 & $15.731^{\mathrm{a} 1}$ & 19.692 & 22.065 & 10.819 & 17.521 & 15.705 & 20.036 & 27.091 & 17.219 \\
\hline $\mathrm{Par}_{\mathrm{H} 2}$ & $34.739^{\mathrm{a} 1}$ & 32.518 & 34.089 & 42.646 & 45.525 & 44.371 & 59.027 & 58.437 & 54.524 \\
\hline D1 & $\begin{array}{c}\text { PIPST } \\
10 \\
\end{array}$ & PIPEST 12 & $\begin{array}{c}\text { PIPEEST } \\
6\end{array}$ & $\begin{array}{c}\text { PIPST } \\
10 \\
\end{array}$ & PIPEST 12 & $\begin{array}{c}\text { PIPST } \\
10 \\
\end{array}$ & $\begin{array}{c}\text { PIPEST } \\
12\end{array}$ & PIPEST 12 & $\begin{array}{c}\text { PIPEST } \\
12 \\
\end{array}$ \\
\hline D2 & $\begin{array}{c}\text { PIPST } \\
6 \\
\end{array}$ & PIPEST 12 & $\begin{array}{c}\text { PIPEST } \\
12 \\
\end{array}$ & $\begin{array}{c}\text { PIPST } \\
10 \\
\end{array}$ & PIPEST 12 & $\begin{array}{c}\text { PIPEST } \\
10 \\
\end{array}$ & $\begin{array}{c}\text { PIPST } \\
12 \\
\end{array}$ & PIPEST 12 & $\begin{array}{c}\text { PIPEST } \\
12 \\
\end{array}$ \\
\hline D3 & $\begin{array}{c}\text { PIPEST } \\
3\end{array}$ & $\begin{array}{c}\text { PIPST } \\
10\end{array}$ & PIPEEST 6 & $\begin{array}{c}\text { PIPEST } \\
10\end{array}$ & PIPEEST 4 & $\begin{array}{c}\text { PIPEST } \\
12\end{array}$ & $\begin{array}{c}\text { PIPST } \\
8\end{array}$ & PIPEEST 5 & $\begin{array}{c}\text { PIPEST } \\
10\end{array}$ \\
\hline D4 & $\begin{array}{c}\text { PIPEST } \\
31 / 2 \\
\end{array}$ & $\begin{array}{c}\text { PIPST } \\
12 \\
\end{array}$ & $\begin{array}{c}\text { PIPEST } \\
6 \\
\end{array}$ & $\begin{array}{c}\text { PIPST } \\
12 \\
\end{array}$ & PIPEST 10 & $\begin{array}{c}\text { PIPEEST } \\
5 \\
\end{array}$ & PIPEEST 5 & PIPEST 10 & $\begin{array}{c}\text { PIPST } \\
10 \\
\end{array}$ \\
\hline 莺莒 & 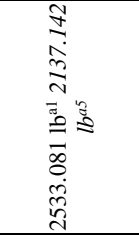 & 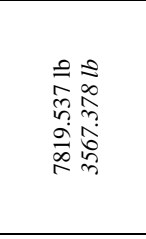 & 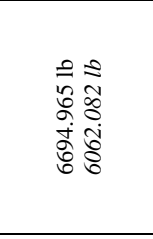 & 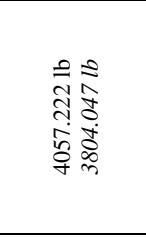 & 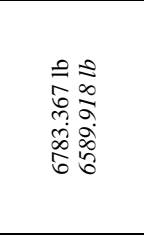 & 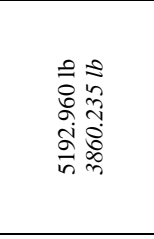 & 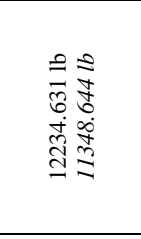 & 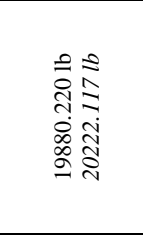 & 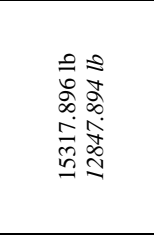 \\
\hline 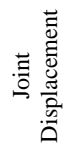 & 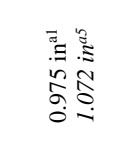 & 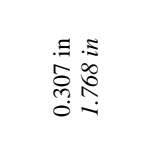 & $\begin{array}{l}\Xi: \Xi \\
n=\infty \\
m= \\
0=\end{array}$ & 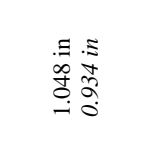 & 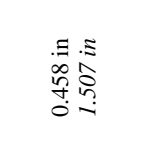 & 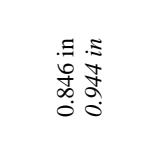 & 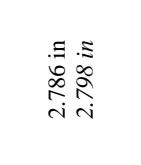 & 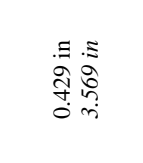 & 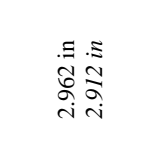 \\
\hline 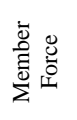 & 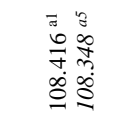 & 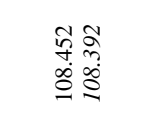 & 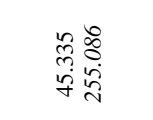 & 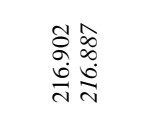 & 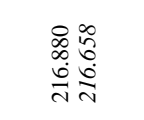 & 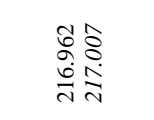 & 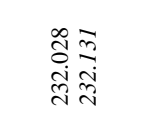 & 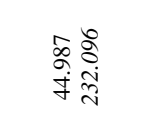 & 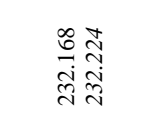 \\
\hline 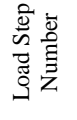 & ప్లె & $m n$ & $N m$ & $m n$ & $m n$ & $m n$ & $m n$ & $N m$ & $m n$ \\
\hline & W & X & $\triangle$ & $\square$ & V & 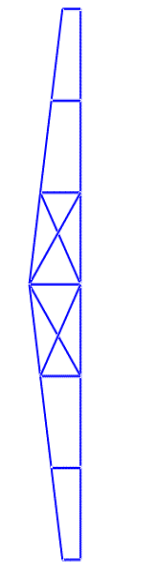 & $\triangle$ & 罗 & 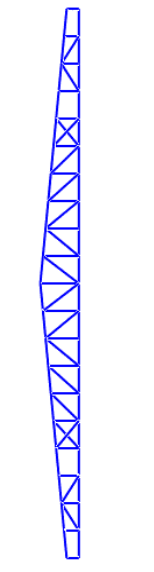 \\
\hline
\end{tabular}


Table 7

The Categorization of Extreme Optimal Designs Considering The Critical Unities (see Table 5-6)

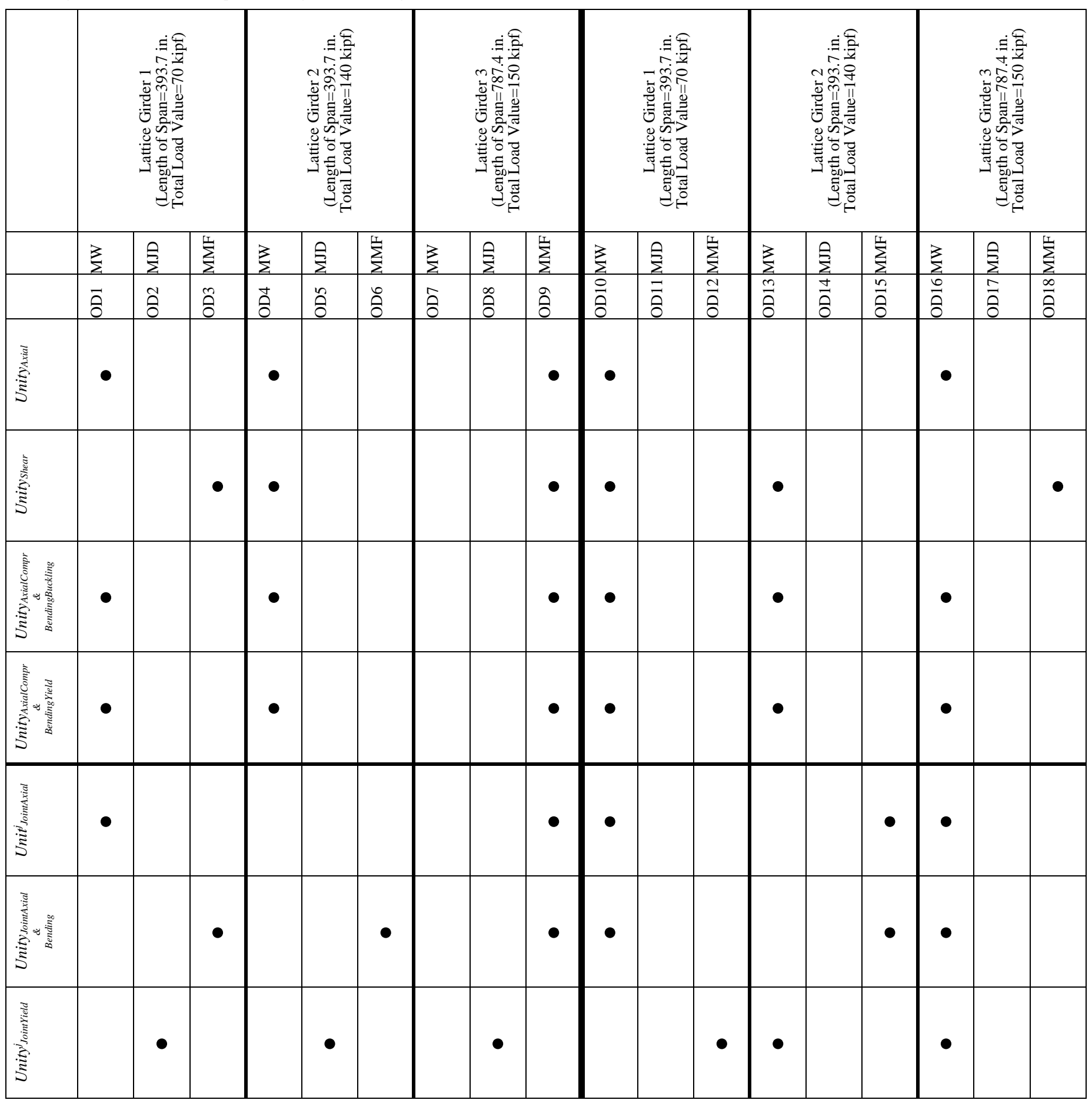

See the definitions for abbreviations in Table 2 


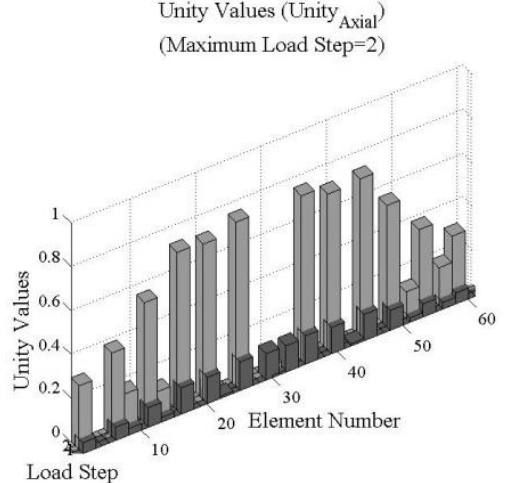

(a)

Unity Values (Unity ${ }_{\text {Axial }}$ ) (Maximum Load Step=3)

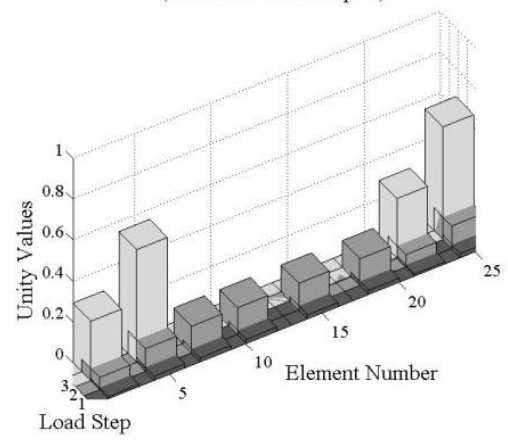

(d)

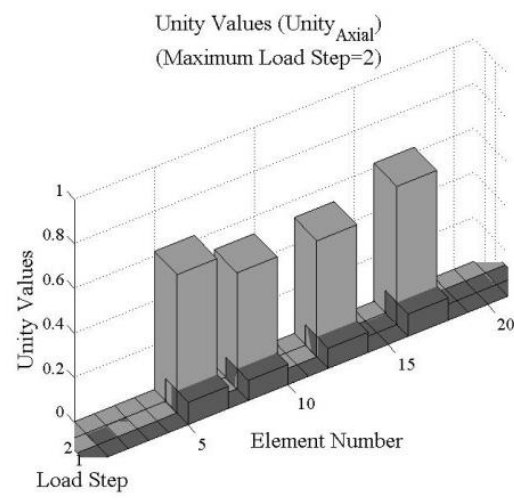

(b)

Unity Values (Unity ${ }_{\text {Axial }}$ )

(Maximum Load Step=3)

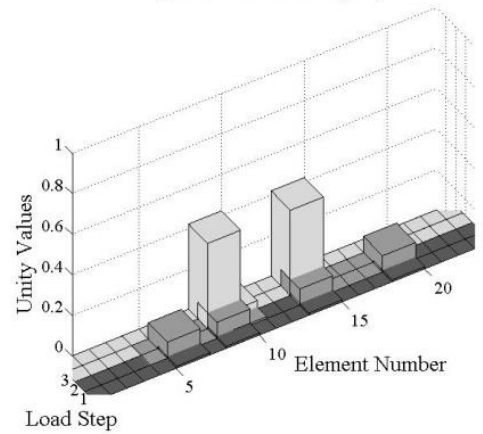

(e)
Unity Values (Unity (Maximum Load Step=3)

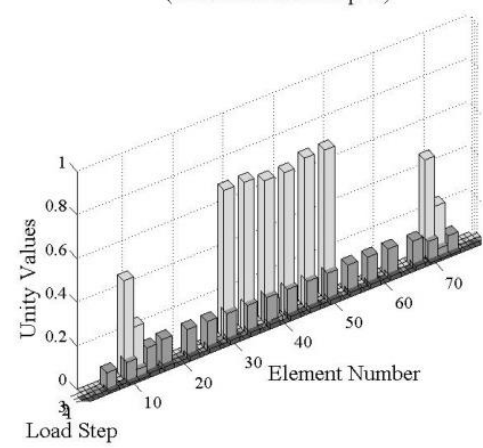

(c)

Unity Values (Unity ${ }_{\text {Axial }}$ ) (Maximum Load Step=3)

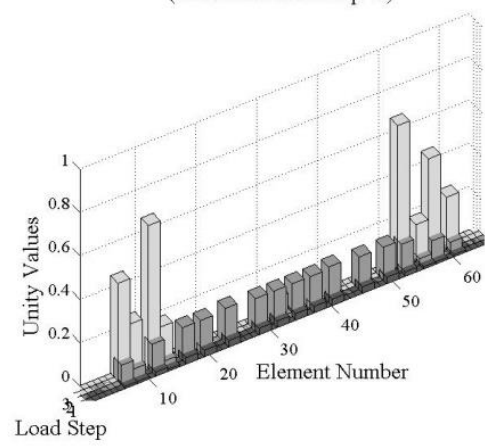

(f)

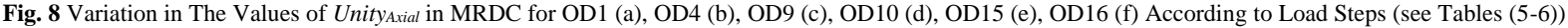

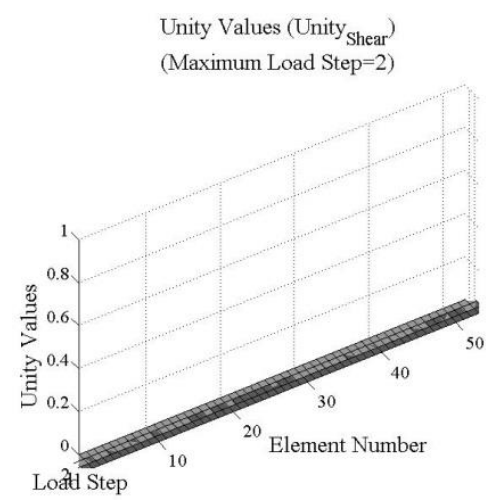

(a)

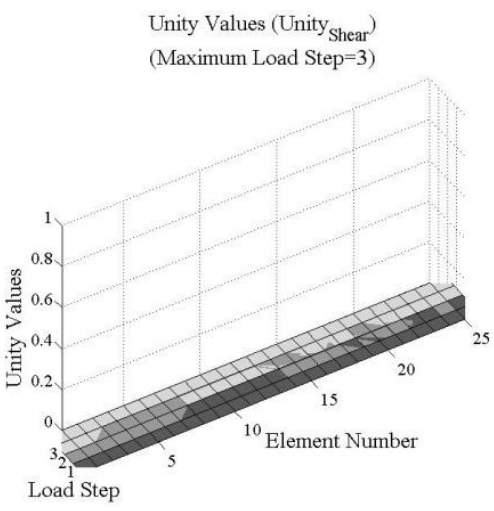

(d)

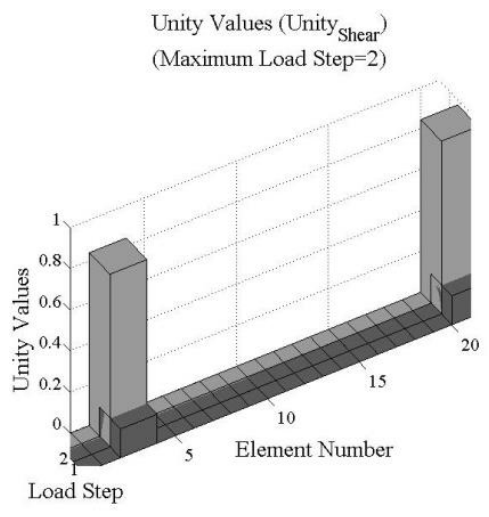

(b)

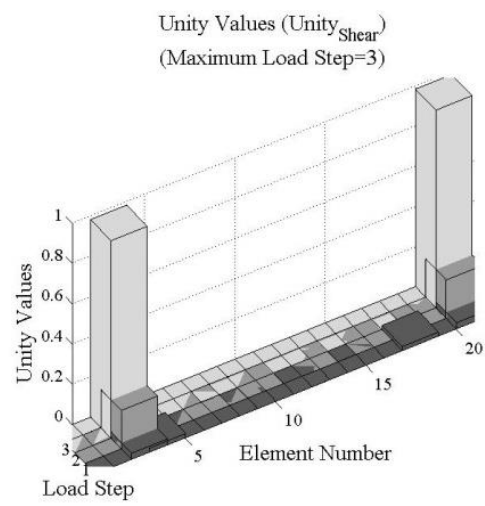

(e)

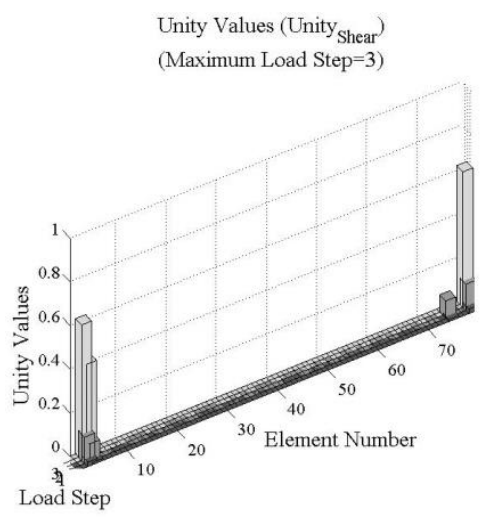

(c)

Unity Values (Unity ${ }_{\text {Shear }}$ ) (Maximum Load Step=3)

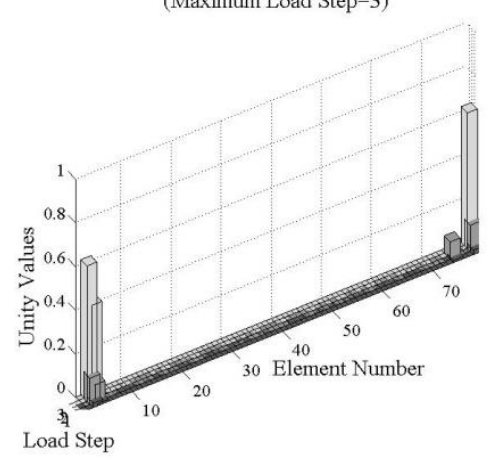

(f)

Fig. 9 Variation in The Values of Unityshear in MRDC for OD3 (a), OD4 (b), OD9 (c), OD10 (d), OD13 (e), OD18 (f) According to Load Steps (see Tables (5-6)) 
Unity Values (Unity AxialCompr\&BendingBuckling $_{\text {) }}$ (Maximum Load Step=2)

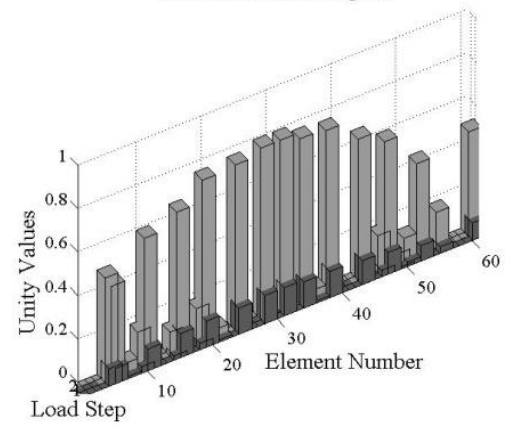

(a)

Unity Values (Unity ${ }_{\text {AxialCompr\&BendingBuckling }}$ (Maximum Load Step=3)

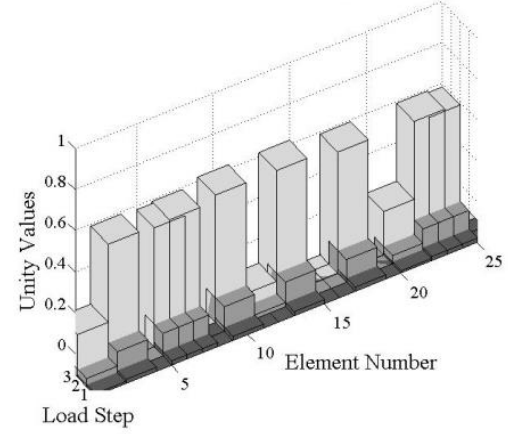

(d)
Unity Values (Unity AxialCompr\&BendingBuckling) (Maximum Load Step=2)

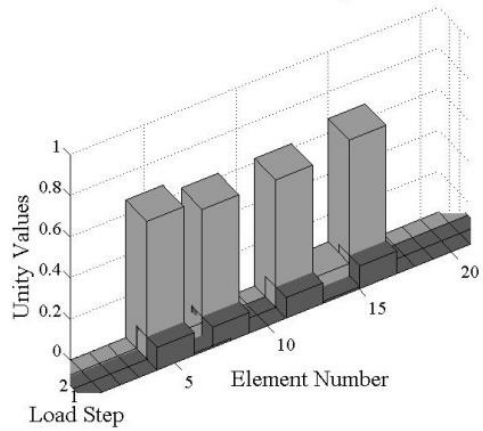

(b)

Unity Values (Unity ${ }_{\text {AxialCompr\&BendingBuckling }}$ ) (Maximum Load Step=3)

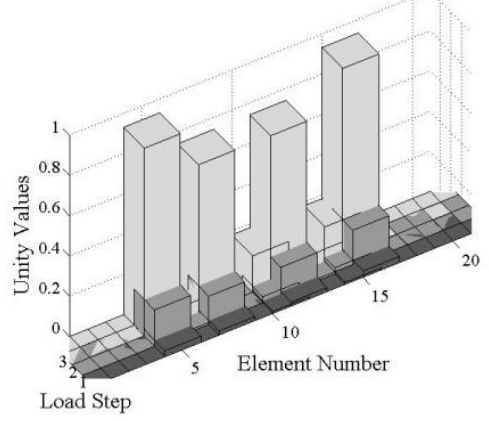

(e)
Unity Values (Unity ${ }_{\text {AxialCompr\&BendingBuckling }}$ ) (Maximum Load Step=3)

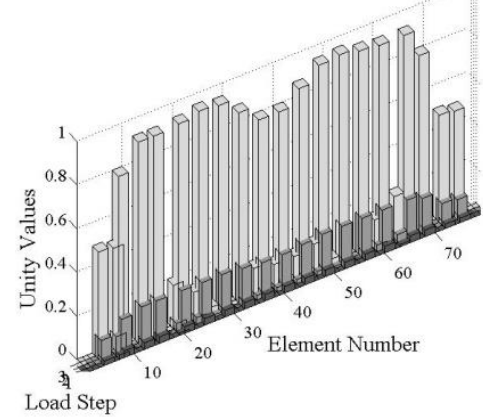

(c)

Unity Values (Unity AxialCompr\&BendingBuckling $_{\text {) }}$ (Maximum Load Step=3)

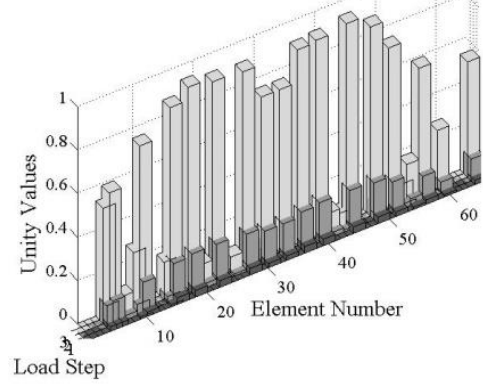

(f)

Fig. 10 Variation in The Values of UnityAxialCompression\&BendingBuckling in MRDC for OD1 (a), OD4 (b), OD9 (c), OD10 (d), OD13 (e), OD16 (f) According to Load Steps (see Tables (5-6))

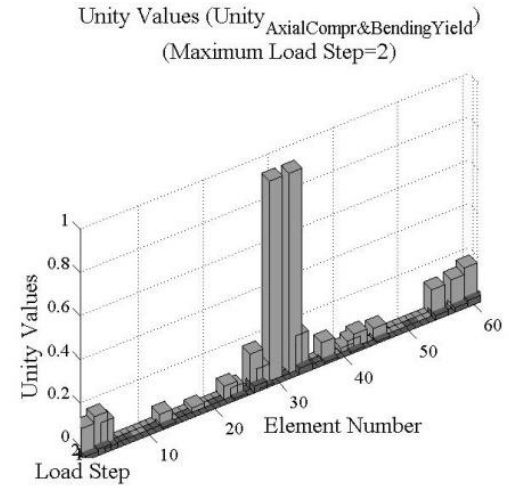

(a)

Unity Values (Unity ${ }_{\text {AxialCompr\&BendingYield }}$ (Maximum Load Step=3)

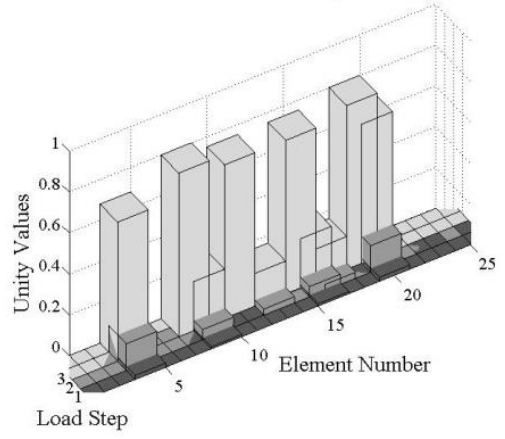

(d)

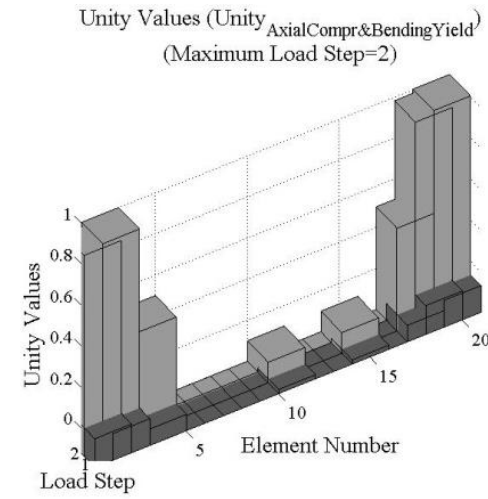

(b)

Unity Values (Unity ${ }_{\text {AxialCompr\&BendingYield }}$ (Maximum Load Step=3)

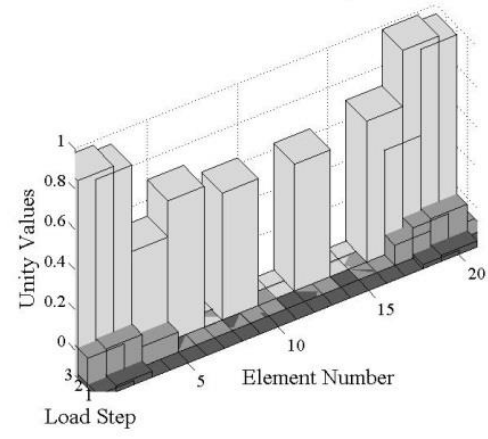

(e)

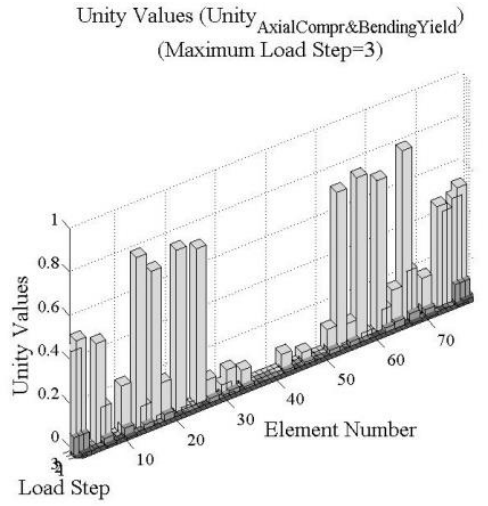

(c)

Unity Values (Unity ${ }_{\text {AxialCompr\&BendingYield }}$ ) (Maximum Load Step=3)

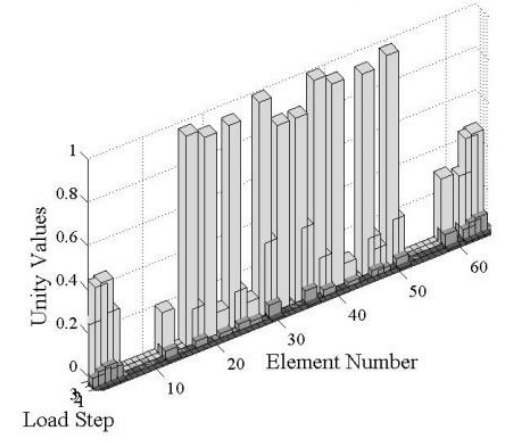

(f)

Fig. 11 Variation in The Values of UnityAxialCompression\&BendingYield in MRDC for OD1 (a), OD4 (b), OD9 (c), OD10 (d), OD13 (e), OD16 (f) According to Load Steps (see Tables (5-6)) 


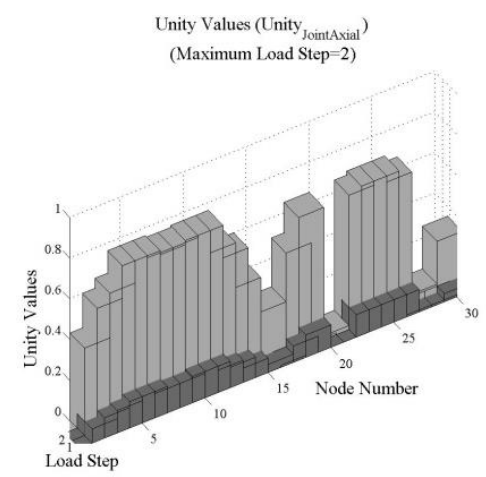

(a) Unity Values (Unity ${ }_{\text {JointAxial }}$ )
(Maximum Load Step=3)

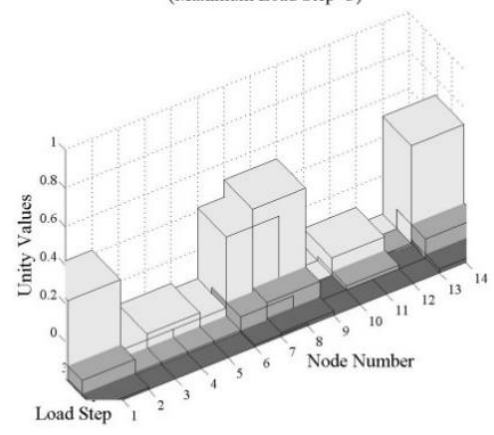

(d)

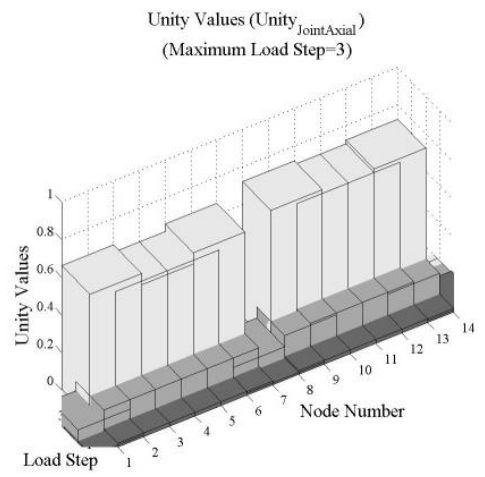

(b)

Unity Values (Unity JointAxial ) (Maximum Load Step=3)

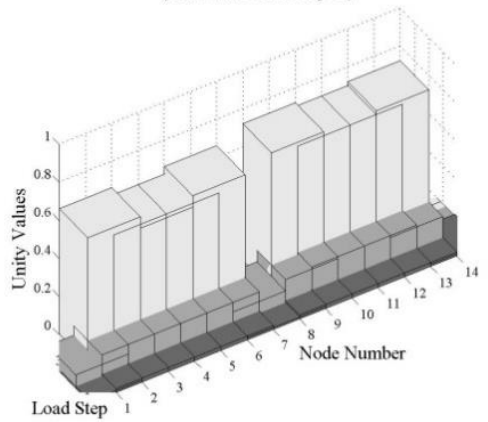

(e)

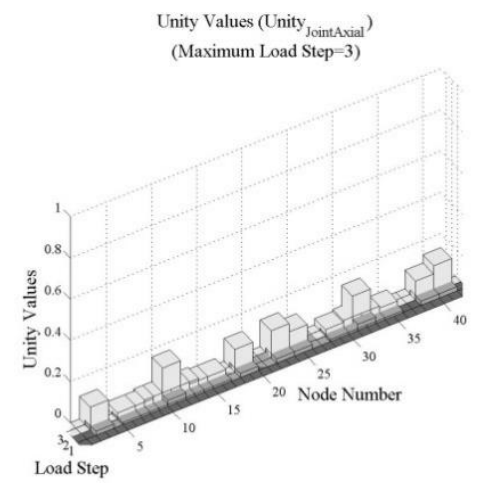

(c)

Unity Values (Unity JointAxial ) (Maximum Load Step=3)

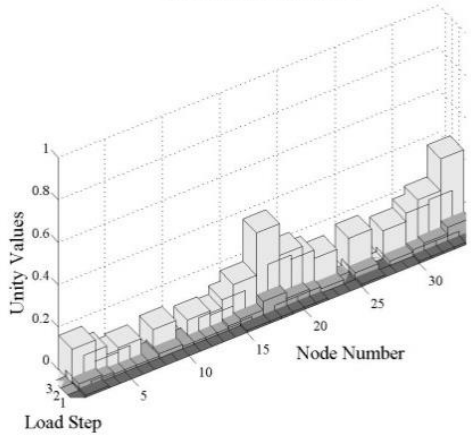

(f)

Fig. 12 Variation in The Values of Unity Jointaxial in JRDC for OD1 (a), OD6 (b), OD9 (c), OD10 (d), OD15 (e), OD16 (f) According to Load Steps (see Tables (5-6))

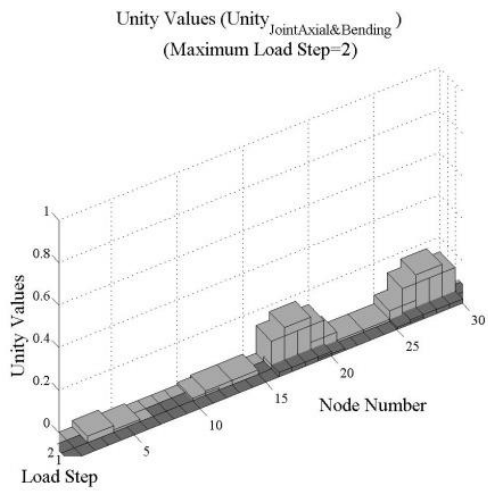

(a)

Unity Values (Unity JointAxialkBending $_{\text {) }}$ (Maximum Load Step $=3$ )

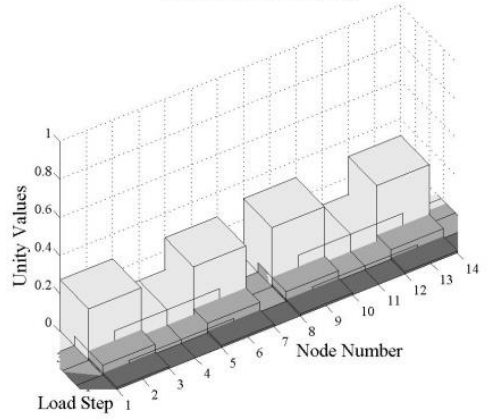

(d)

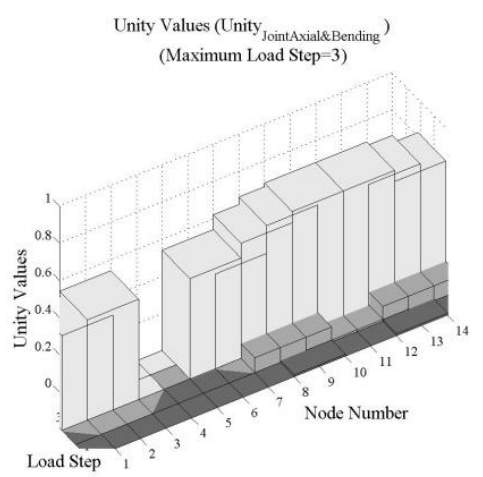

(b)

Unity Values (Unity JointAxial\&Bending $_{\text {) }}$ (Maximum Load Step=3)

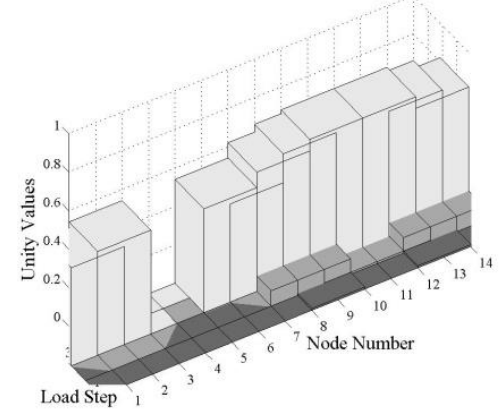

(e)

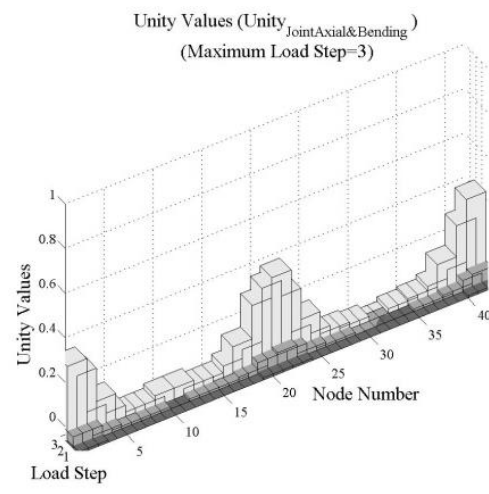

(c)

Unity Values (Unity (Maximum Load Step=3)

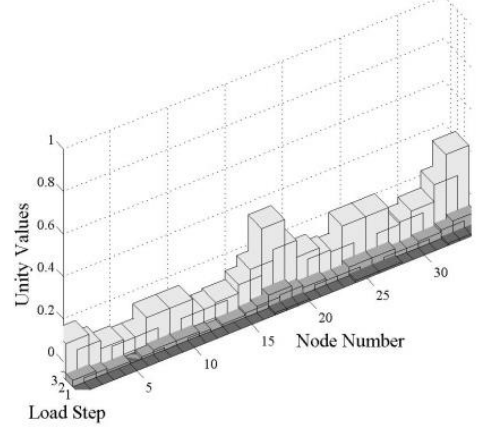

(f)

Fig. 13 Variation in The Values of Unity JointAxial\&Bending in JRDC for OD3 (a), OD6 (b), OD9 (c), OD10 (d), OD15 (e), OD16 (f) According to Load Steps (see Tables (5-6)) 


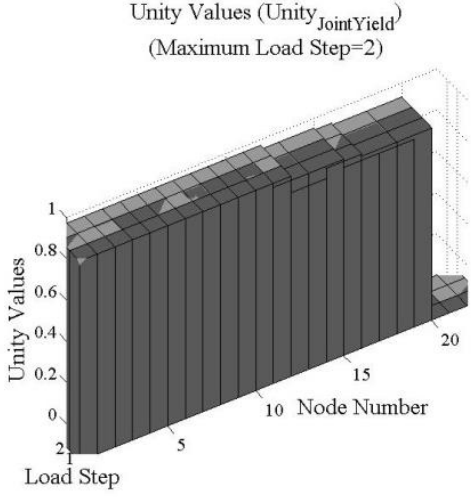

(a)

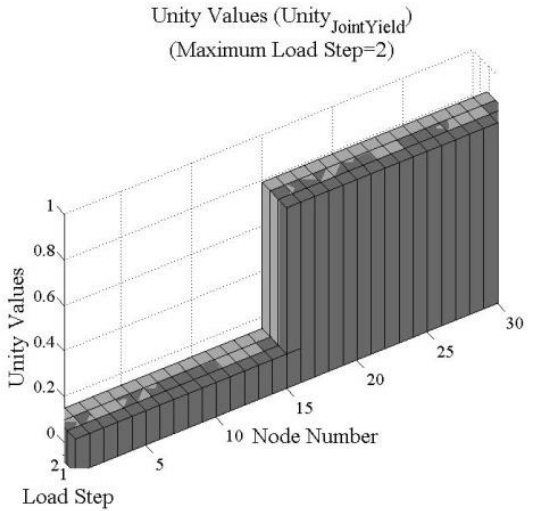

(d)

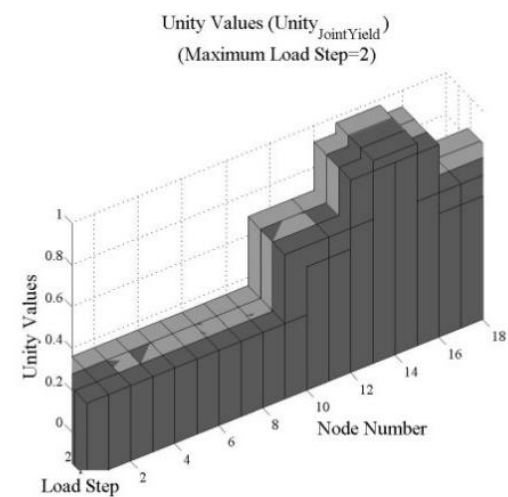

(b)

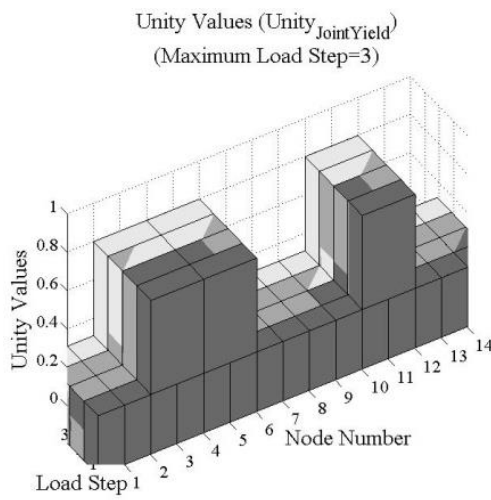

(e)

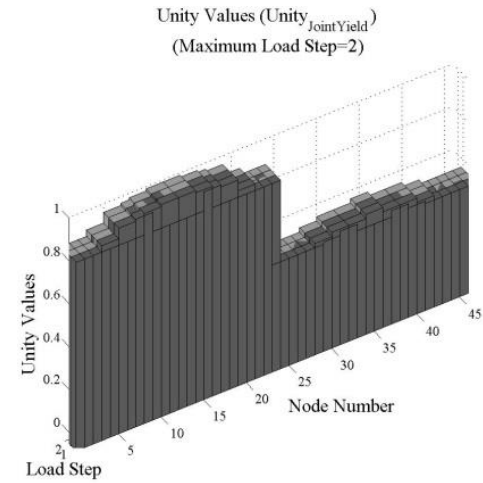

(c)

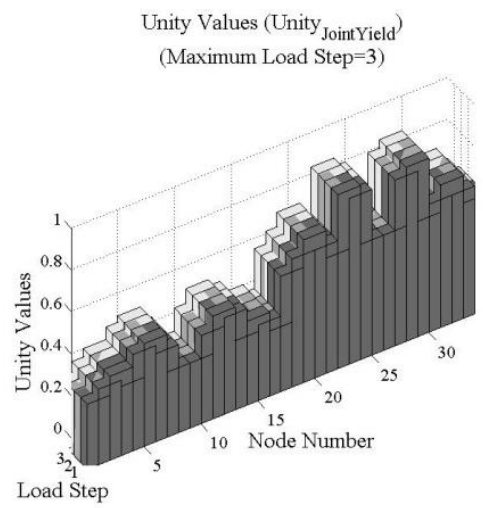

(f)

Fig. 14 Variation in The Values of Unity $y_{\text {JointYield }}$ in JRDC for OD2 (a), OD5 (b), OD8 (c), OD12 (d), OD13 (e), OD16 (f) According to Load Steps (see Tables (5-6))

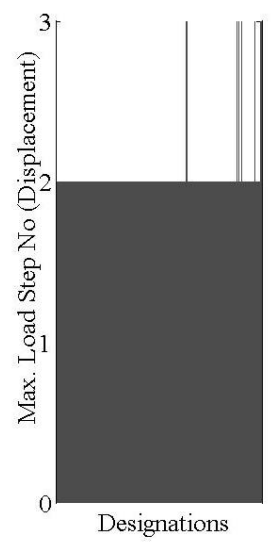

(a)

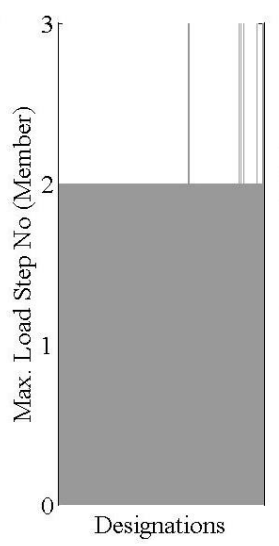

(b)

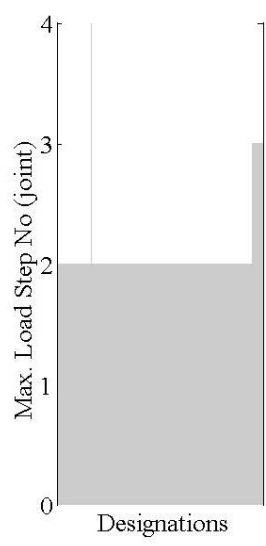

(c)

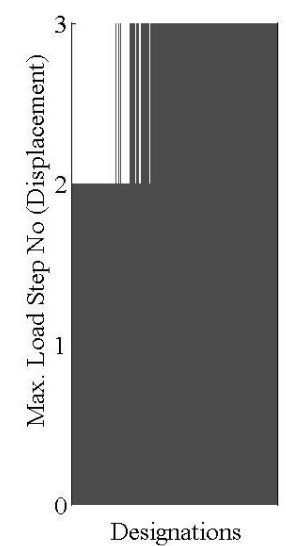

(d)

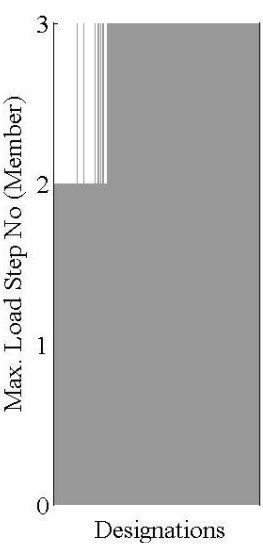

(e)

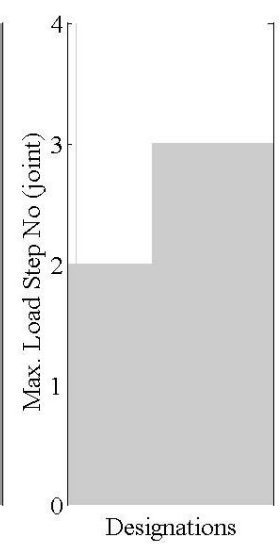

(f)

Fig. 15 The Maximum Load Step Numbers (Lattice Girder 2 (a-c) and (Lattice Girder 2 (d-f)) (see Tables (5-6))

\section{Conclusion}

The design of geometrically nonlinear lattice girders was optimized using the optimization tool named ImpNSGAII, which was obtained in a way of hybridizing the optimization algorithm named NSGAII and a neural network approach [17]. The member-related design constraints (MRDC) were taken from the provisions of API RP2A-LRFD specification [28]. In this study, the design complexity for the proposed optimal design approach in Reference [17] is increased thereby including the joint-related design constraints (JRDC) into the current design constraints. Hence, the influence of JRDC on the optimality quality of designs is investigated. Furthermore, the computing efficiencies of both ImpNSGAII and NSGAII are also compared by optimizing the benchmark lattice girder and general lattice girder. The following primary observations are summarized as given below: i) In spite of increasing the design complexity, ImpNSGAII achieves to obtain the optimal designs with higher load-resistance, economic and serviceability features through its self-adaptive mechanism. However, the simultaneous use of JRDC along with MRDC causes a divergence in the construction cost of tubular lattice girder due to an increase in the entire weight of optimal lattice girder.

ii) It is shown that an inclusion of diagonal members into the framing configuration of automatically generated lattice girder increases the capacities of both member and joint-related strengths. However, the lack of diagonal members in the framing configuration of lattice girder along with an assignment of relatively lower cross-sectional thickness to the members causes to increase the sensitivity in both member and joint-related unities.

iii) It is observed that the joint yield-related design constraint achieves to be the most determinative one among the other joint-related design constraints due to its higher values. 
iv) Considering the extreme optimal designs, the solely use of proposed three objective functions, entire weight of lattice girder, its joint displacements and its member forces causes to prevent a tradeoff analysis among these objective functions. But, it is shown that a simultaneous use of these multiple objective functions correspondingly provides both to make a concise and reasonable evaluation of MRDC and JRDC-related design constraints and to obtain optimal lattice girder designs with relatively higher joint and member strength capacities.

Consequently, this challenging optimal design approach achieves to explore the optimal lattice girder designs with higher load-resistance capability thereby increasing the design reliability through the usage of JRDC along with MRDC. Therefore, ImpNSGAII is recommended to obtain an optimal design configuration for the lattice girder according to a pre-defined spanning length and loading adjustment.

\section{References}

[1] Nageim, H.K. and Macginley, T.J., Steel structures, practical design studies, 3th ed. EF Spon Press, 2005.

[2] Groover, M.P., Fundamentals of modern manufacturing, materials, processes and systems, 4th ed. John Wiley and Sons Inc., 2010

[3] Owens, G.W., Steel Designer's Manual, 6th ed. Blackwell Science, 2005.

[4] Nelson, JKa and McCormac, J.C., Structural Analysis: Using Classical and Matrix Methods, 3th ed. John Wiley and Sons Inc., 2003.

[5] Kaveh, A. and Talatahari, S., "Optimal design of schwedler and ribbed domes via hybrid big bang-big crunch algorithm", Journal of Constructional Steel Research, 66(3), pp. 412-419, 2010

[6] Carbas, S. and Saka, M.P., "Optimum topology design of various geometrically nonlinear latticed domes using improved harmony search method", Structural and Multidisciplinary Optimization, 45(3), pp. 377-399, 2012.

[7] Jorabchi, K. and Suresh, K., "A robust method to pass limit-point instability", Finite Elements in Analysis and Design, 47(11), pp. 1253-1261, 2011

[8] Koohestani, K., "A hybrid method for efficient solution of geometrically nonlinear structures", International Journal of Solid and Structures, 50(1), pp. 21-29, 2013

[9] Nelson, J.K. and McCormac, J.C., "Structural Analysis: Using Classical and Matrix Methods", 3th ed. John Wiley and Sons Inc., 2003.

[10] Rao, S.S., "Engineering Optimization: Theory and Practice", 4th ed., John Wiley and Sons Inc., 2009.

[11] Arora, J., "Introduction to Optimum Design", 3th ed., Academic Press, 2011.

[12] Saka, M.P. and Dogan, E. "Recent Developments in Metaheuristic Algorithms: A Review", Computational Technology Reviews, 5, pp. 31-78, 2012. doi:10.4203/ctr.5.2.

[13] Packer, J.A. and Henderson, J.E. "Hollow structural section connections and trusses: a design guide", Canadian institute of steel construction, 1997

[14] Wardenier, J., Dutta, D., Yeomans, N., Packer, J.A. and Bucak, Ö. International Committee for Research and Technical Support for Hollow Section Structure: CIDECT Design Guide 6, for structural hollow sections in mechanical applications, 1998.

[15] Wardenier, J., International Committee for Research and Technical Support for Hollow Section Structure: Hollow sections in structural applications, 2001

[16] Kurobane. Y., Packer, J.A., Wardenier, J. and Yeomans, N., International Committee for Research and Technical Support for Hollow Section Structure: CIDECT, Design Guide 9, for structural hollow section column connections, 2005.

[17] Talaslioglu, T. "Optimization of geometrically nonlinear lattice girders. Part I: considering member strengths, Journal of Civil Engineering and Management", 21(4), pp. 423-443, 2015, DOI: $10.3846 / 13923730.2014 .890648$
[18] Talaslioglu, T. "Global stability-based design optimization of truss structures using multiple objectives", Sadhana Proceedings in engineering sciences, 38(1), pp. 37-68, 2013.

[19] Merritt, F.S. and Ricketts, J.T., Building Design and Construction Handbook, 6th ed McGraw-Hill, 2000.

[20] Bailey, B. and Raich, A.M. "Modeling of user design preferences in multiobjective optimization of roof trusses", Journal of Computing Civil Engineering, 26, pp. 584-596, 2012.

[21] Sanchis, J., Martínez, M.A., Blasco, M.X. and Reynoso-Meza G. "Modeling preferences in multi-objective engineering design", Engineering Applications of Artificial Intelligence, 23(8), pp. 1255-1264, 2010.

[22] Laumanns, M., Thiele, L. and Zitzler, E. "An efficient, adaptive parameter variation scheme for metaheuristics based on the epsilon-constraint method", European Journal of Operational Research, 169, pp. 932-942, 2006.

[23] Noll,e L. and Bland, J.A. "Self-adaptive stepsize search for automatic optimal design", Knowledge-Based Systems, 29, pp. 75-82, 2012.

[24] Pholdee, N and Bureerat S. "Hybridization of real-code population-based incremental learning and differential evolution for multi-objective design of trusses", Information Sciences, 223 , pp. 136-152, 2013

[25] Tan, K.C., Lee, T.H. and Khor, E.F. "Evolutionary Algorithms for Multi-Objective Optimization: Performance Assessments and Comparisons", Artificial Intelligence Review, 17(4), pp. 253-290, 2002

[26] Gustavo, R.Z., Nebro, A.J., Luna, F. and Coello, C.A.C. "A survey of multi-objective metaheuristics applied to structural optimization", Structural and Multidisciplinary Optimization, 49, pp. 537-558, 2014, DOI 10.1007/s00158-013-0996-4.

[27] Coello, C.A., Lamont, G.B. and Van Veldhuizen D.A. "Evolutionary algorithms for solving multi-objective problems". Springer.Davison B., 2007.

[28] American Petroleum Institute (API): API RP2A-LRFD, Recommended Practice for Planning, Designing and Constructing Fixed Offshore Platforms. Load and Resistance Factor Design, $1^{\text {st }}$ Edition, 1993.

[29] Srinivas, N. and Deb, K. "Multiobjective function optimization using nondominated sorting genetic algorithms", Evol. Comput., 2, pp. 221-248, 1995

[30] Talaslioglu, T. "Optimal dome design considering member-related design constraints". Front. Struct. Civ. Eng. 13, pp. 1150-1170 2019, https://doi.org/10.1007/s11709-019-0543-5

[31] Talaslioglu, T. "Design Optimization of Tubular Lattice Girders", Adv. Steel Constr, 15(3), pp. 274-287, 2019 ttps://doi.org/10.18057/IJASC.2019.15.3.8

[32] Talaslioglu, T. "Optimal design of steel skeletal structures using the enhanced genetic algorithm methodology", Front. Struct. Civ. Eng., 13, pp. 863-889, 2019, https://doi.org/10.1007/s11709-019-0523-9

[33] Talaslioglu, T. "A Unified Optimal Design Approach for Geometrically Nonlinear Skeletal Dome Structures" Periodica Polytechnica Civil Engineering, 63(2), pp. 518-540, 2019 https://doi.org/10.3311/PPci.13329

[34] Talaslioglu, T. "A comparative study of multi-objective evolutionary metaheuristics for lat tice girder design optimization" Structural Engineering and Mechanics, 77(3), 2021, DOI https://doi.org/10.12989/sem.2021.77.3.001

[35] Saka, M.P. and Geem, V.Z. "Mathematical and Metaheuristic Applications in Design Optimization of Steel Frame Structures: An Extensive Review", Mathematical Problems in Engineering, 2013, http://dx.doi.org/10.1155/2013/271031

[36] Gandomi, A.H., Yang, X.S., Talatahari S and Alavi, A.H. "Metaheuristic Applications in Structures and Infrastructures", Elsevier, 2013

[37] MATLAB, Natick, Massachusetts: The MathWorks Inc, 2015.

[38] Lee, K.S. and, Geem, Z.W. "A new structural optimization method based on the harmony search algorithm", Computer and Structure, 82, pp. 781-98, 2004.

[39] Khot, N.S. and Berke, L. "Structural optimization using optimality criteria methods" in Atre E et al. (Eds.) New directions in optimum structural design, John Wiley \& Sons Inc., 1984.

[40] Li, L.J., Huang, Z.B., Liu, F. and Wu, Q.H. "A heuristic particle swarm optimizer for optimization of pin connected structures", Computers and Structures, 85, pp. 340-349, 2007.

A comparative study of multi-objective evolutionary metaheuristics for lattice girder design optimization 